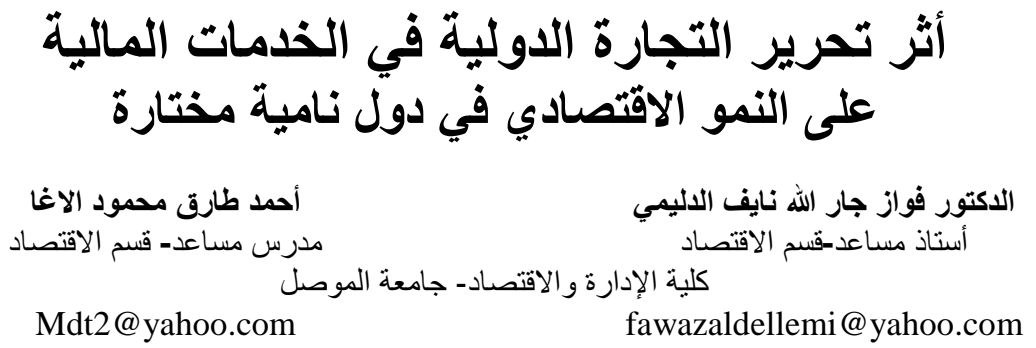

\begin{abstract}
المستخلص أنجار

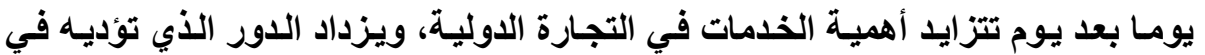

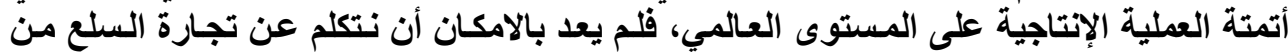

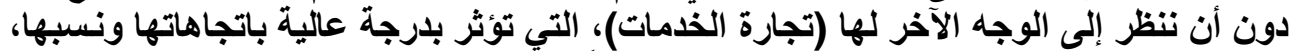

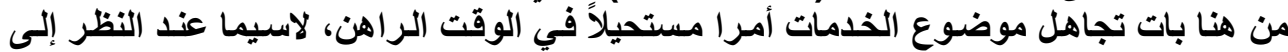

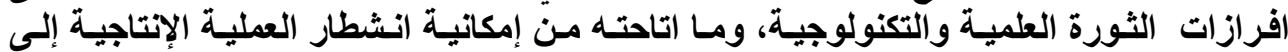

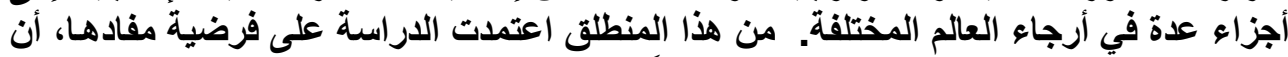

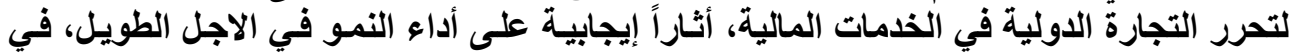

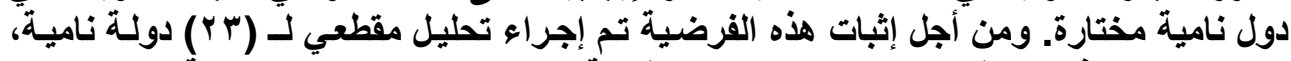

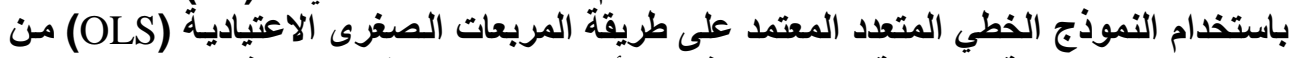

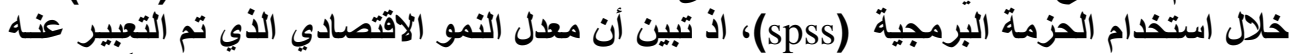

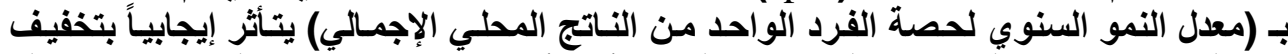

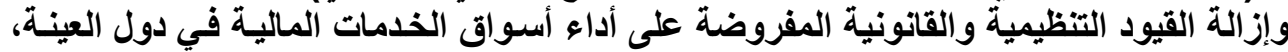

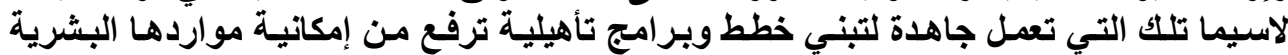

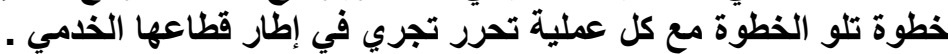

\title{
The Effect of Freeing the International Trade of Financial Services on the Economic Growth of Sample Developing Countries
}

\author{
Fawaz J. Al - Dulaimi (PhD) \\ Professor \\ Department of Economics \\ University of Mosul
}

\author{
Ahmed Tariq \\ Assistant Lecturer \\ Department of Economics \\ University of Mosul
}

\begin{abstract}
Day after day, the importance of services of international trade increases and the number of the countries that automate the production process at the international level also increases. Therefore, there is no room for talking about commodity without taking the services trade into consideration that greatly affects the direction and rates. Hence, it is
\end{abstract}




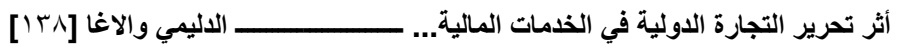

impossible however to ignore that issue of services at this time, especially when we look at the outcome of the technological and the following facilitation of the production process into several parts all over the world. On this basis, the study adopted a hypothesis stating that a free international trade in financial services has a positive effect on the growth performance in the long ran in given number of countries. In order to verify this hypothesis, a profit analyses of (23) developing countries has been made using the multi - linear model based on the ordinary least squares (OLS) and the (SPSS). It is shown that the rate of economic growth with represent the rate of the annual growth in the total domestic production per capita is positively affected by the elevation or elimination of the legal and regulating constrains imposed on the performance of the monetary services markets and communication markets in the developing countries (sample counters), especially the countries that endeavor to put plans and qualifying programmers that can improve their human resources step by step with every liberating act in the framework their services sector.

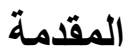

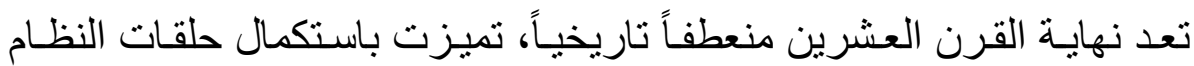

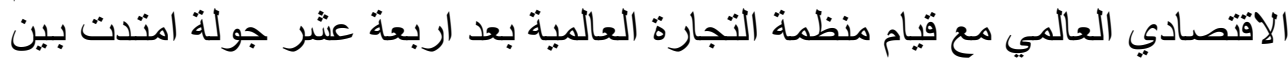

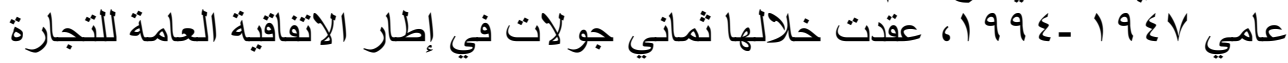

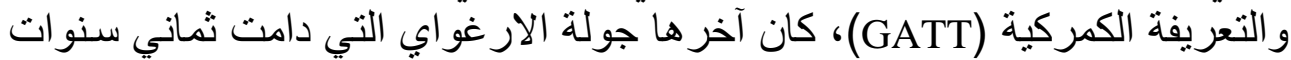

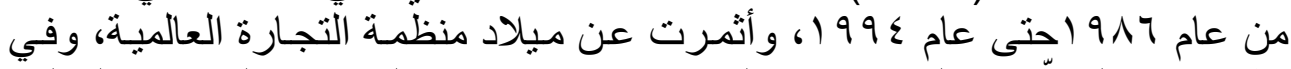

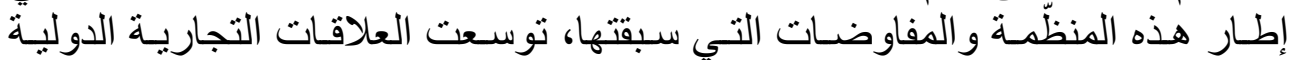

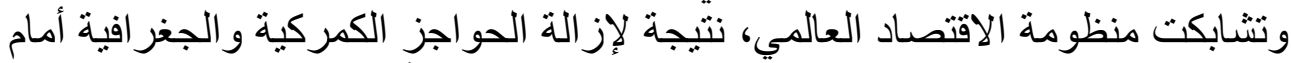

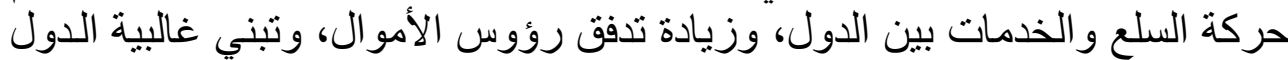

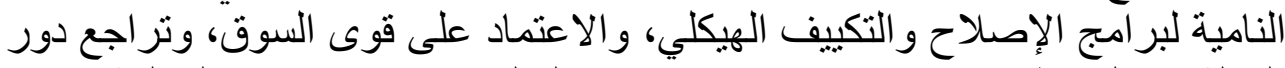

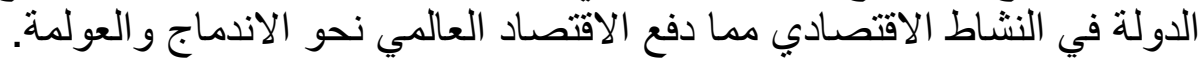

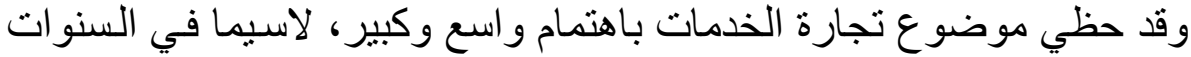

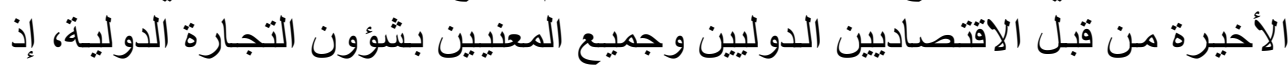

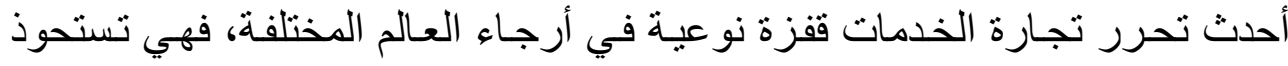

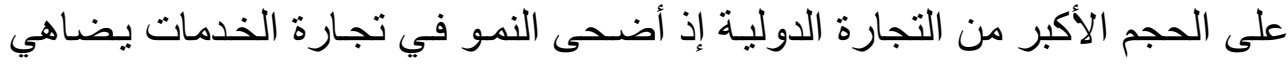

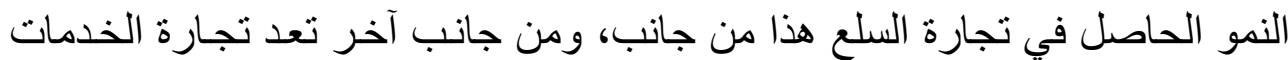

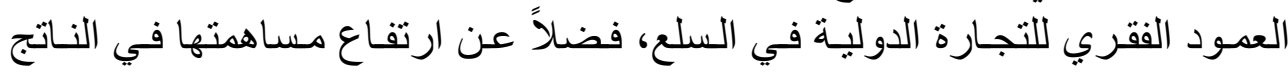

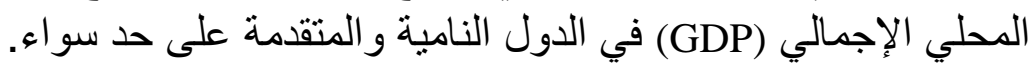

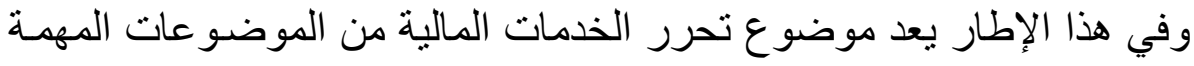

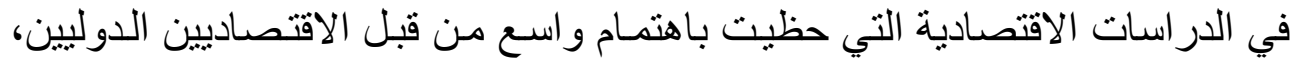

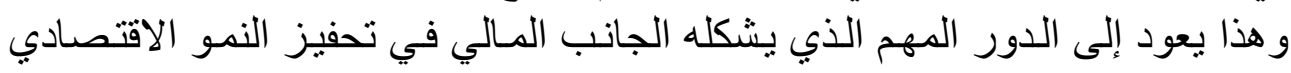

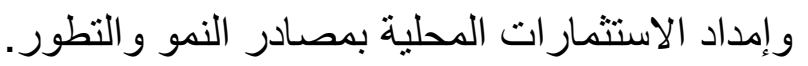

\footnotetext{
أهمية البحث

يعود الاهتمام المتز ايد بموضوع تحرر تجارة الخدمات المالية إلى سببين:
} 


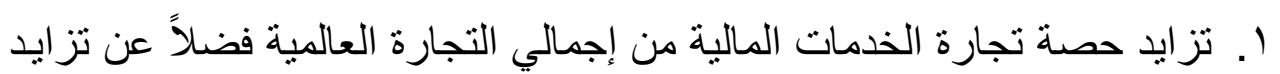
نسبة مساهمتها في الناتج المحلي الاجمات التهالي.

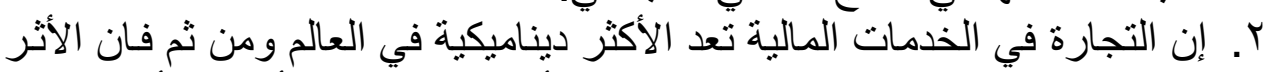

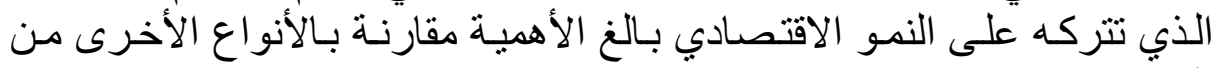

تتمثل مشكلة البحث في معرفة البه الآتي:

\section{مشكلة البحث}

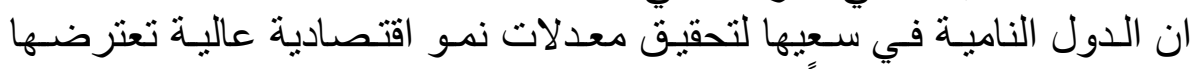

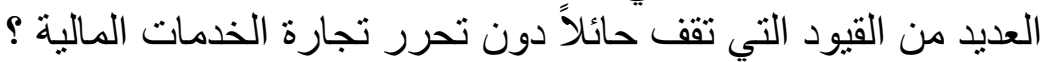

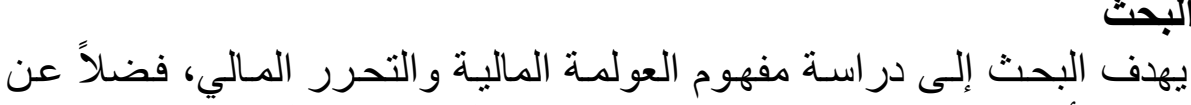
تحديد وقياس أثر تحرر التجارة الدولية في الخدمات المالية على النمو الاقتصادي في في التهاي بلدان نامية مختارة. فرضية البحث

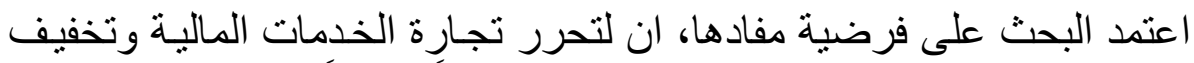

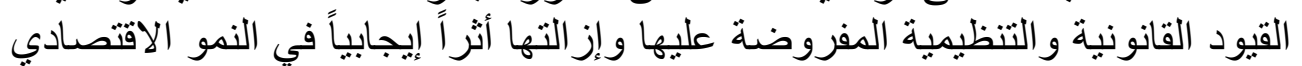

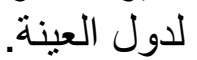

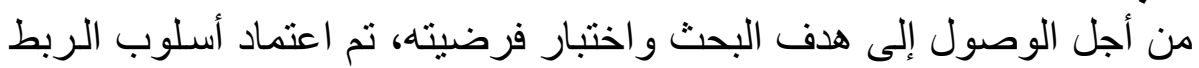
أسلوب البحث: البه

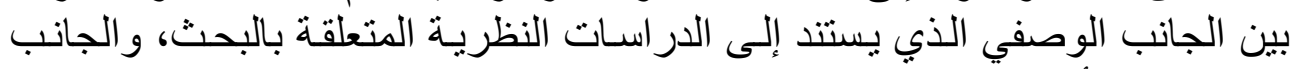

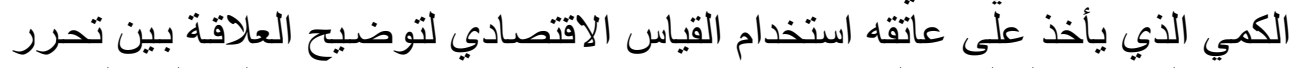

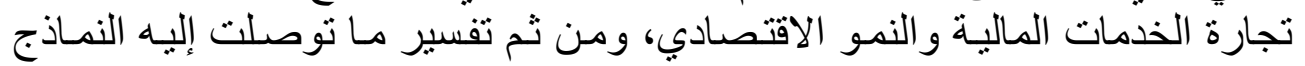
القياسية.

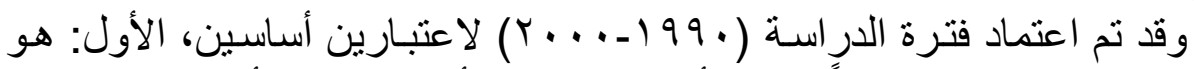

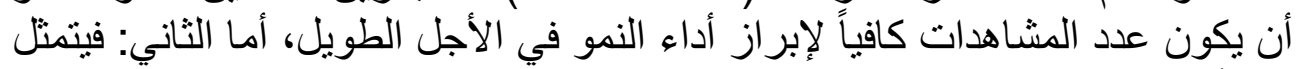

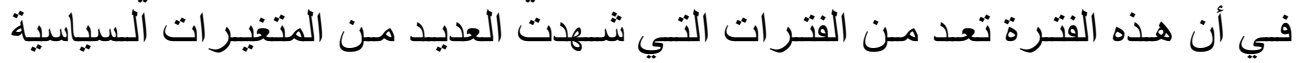

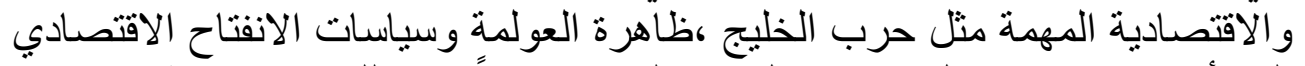

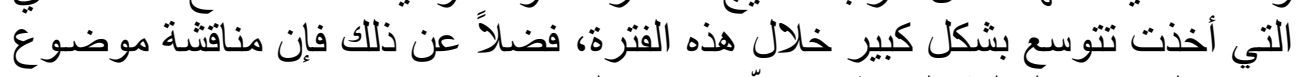

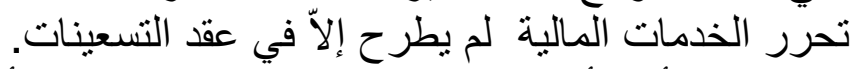

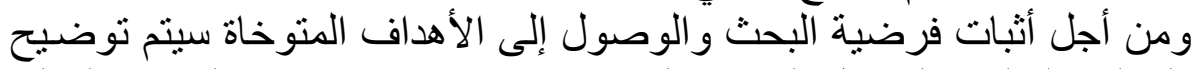

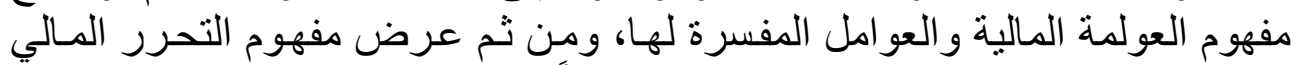

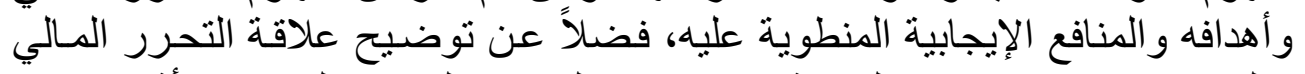

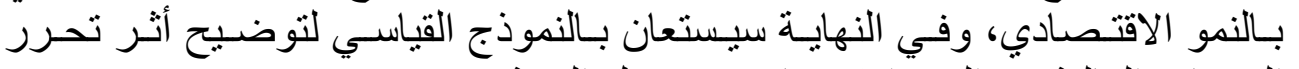

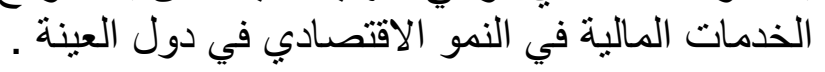

يعد موضوع تحرر الخدمات المالية من الموضـوعات المهمـة في الدر اسـات

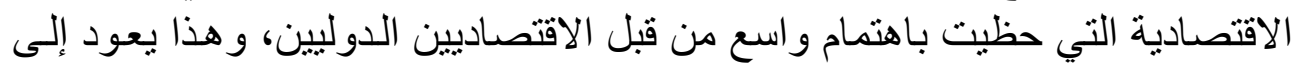




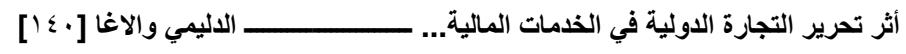

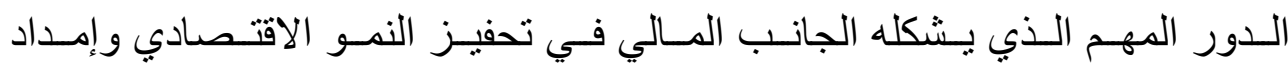

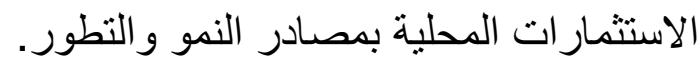

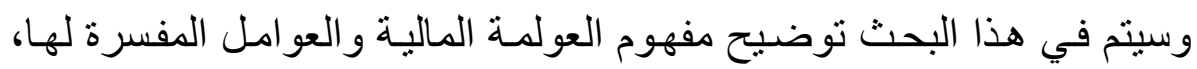

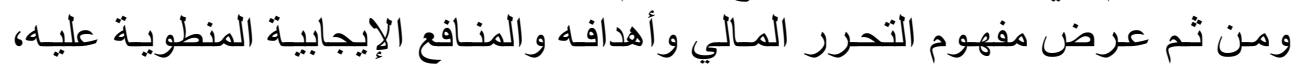

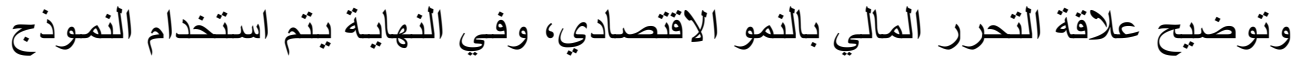

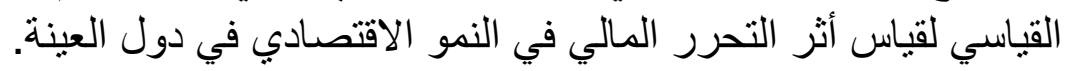

\section{ا ــ العولمة المالية}

حظي مفهوم العولمة الاقتصادية باهتمام بالغ لدى العديد من الاقتصـاديين في

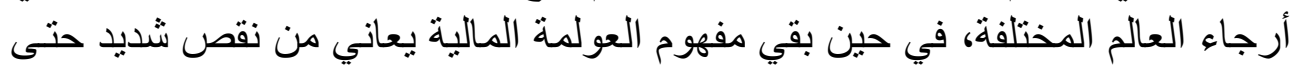

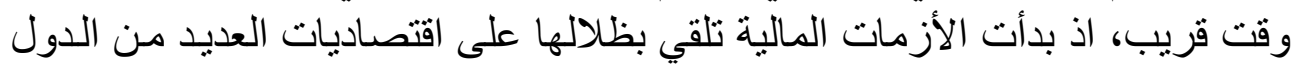

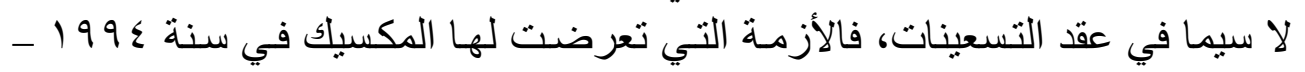

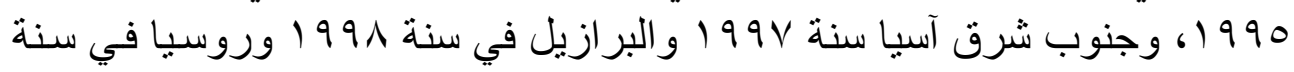

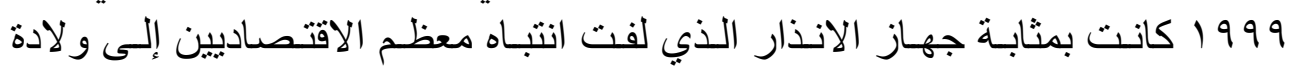
ظاهرة جديدة تدعى بالعولمة المالية التي تعد من أهم مظاهر العولمة الإنس الأتصادية.

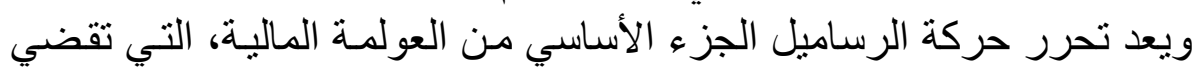

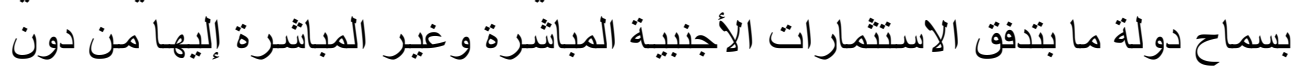

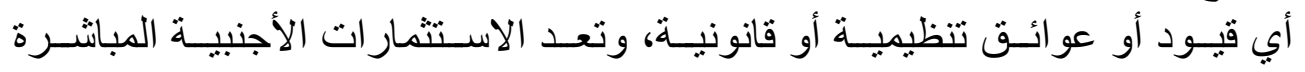

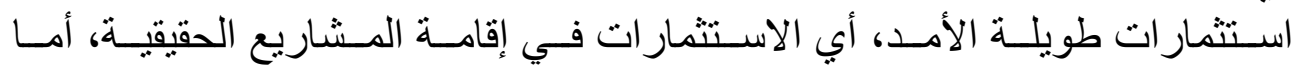

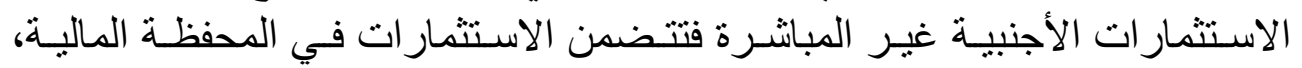

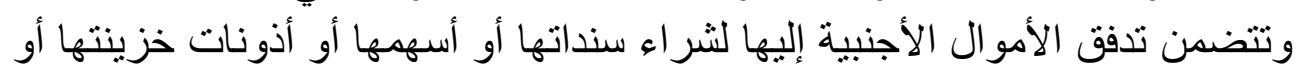

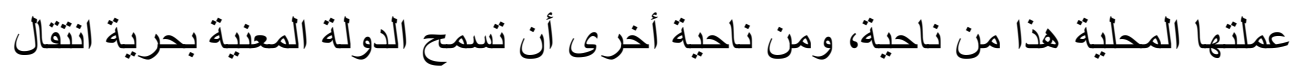

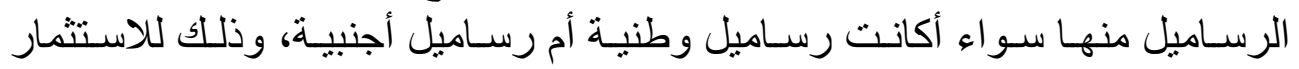

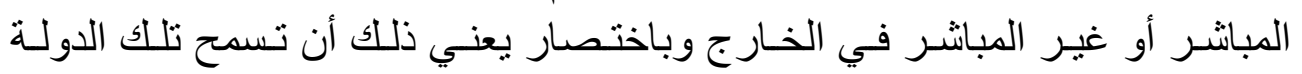

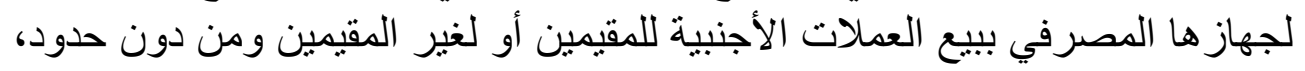

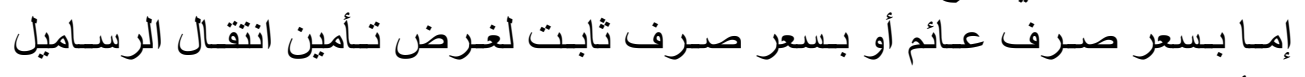

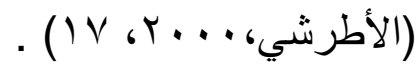
وقد أتاح التقدم التكنولوجي الكبير في مجال الاتصالات الدولية سـهولة كبيرة

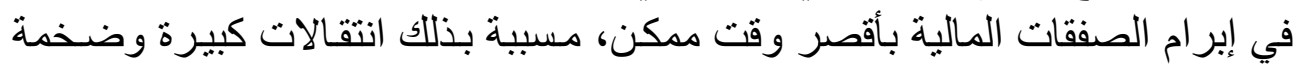

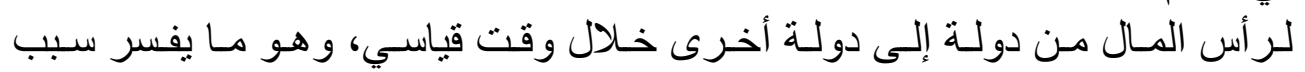

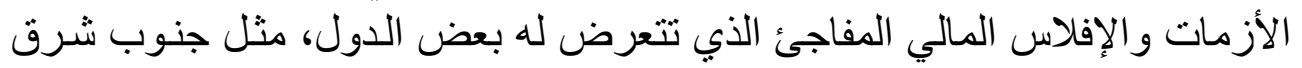

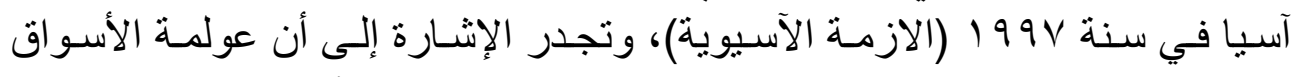

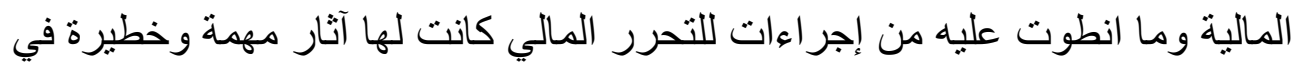

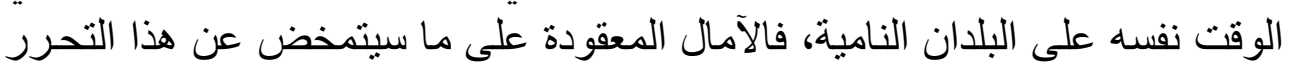


$(r \cdot)^{9} \cdot$ [1 [1 [ كلية الادارة والاقتصاد/جامعة الموصل

كبيرة جداً، و هي تتمثل بالزيادة في قدرة الدول النامية على الاتصـال بسوق المـال

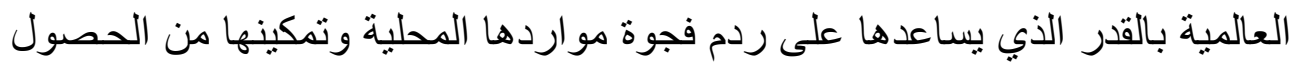

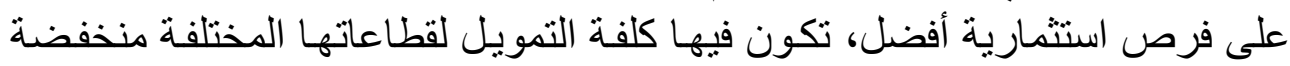

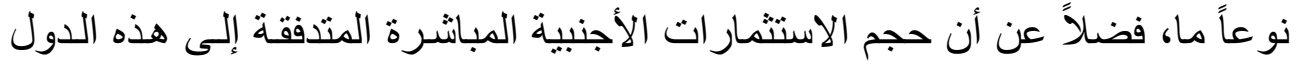
سوف بساعد في انعاش اقتصادياتها.

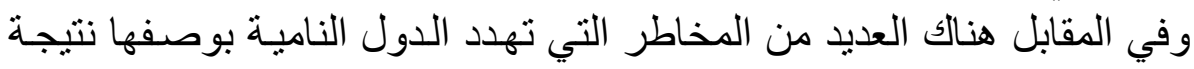

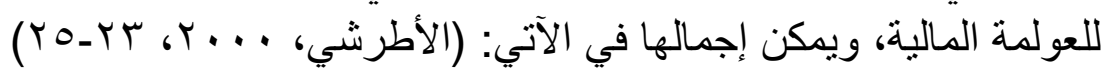

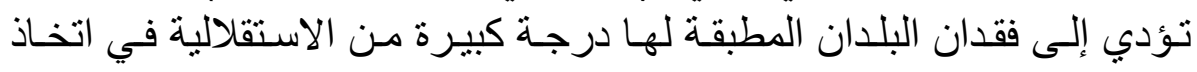

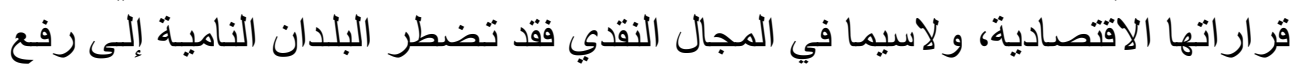

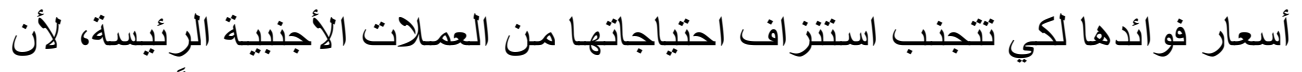

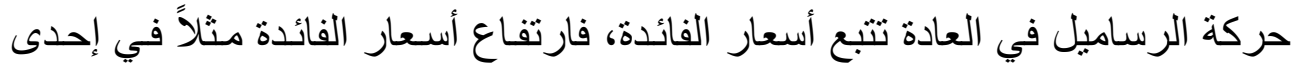

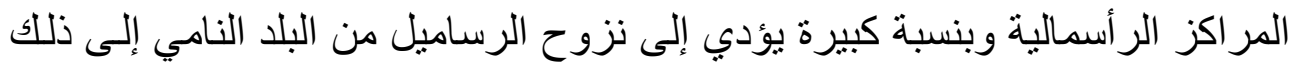

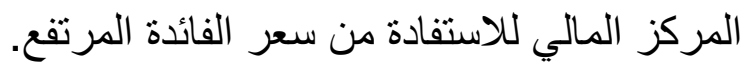

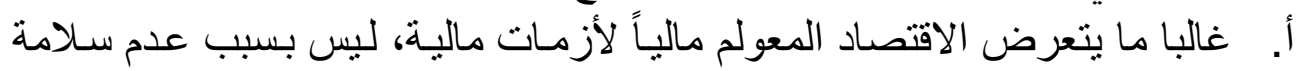

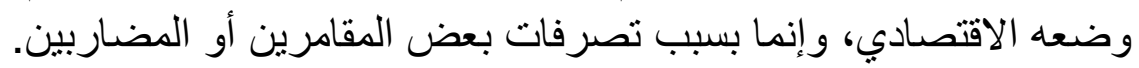

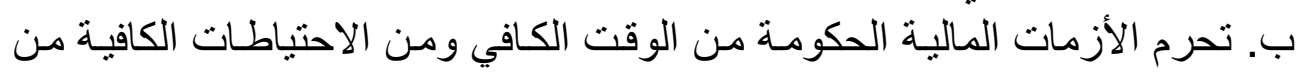

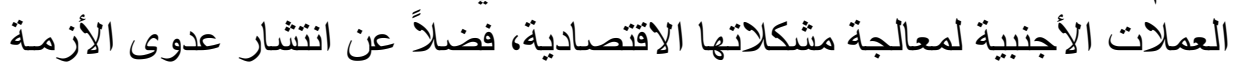

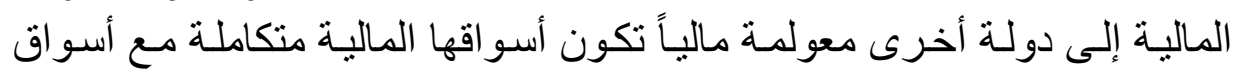

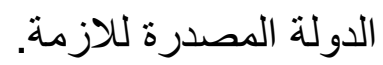

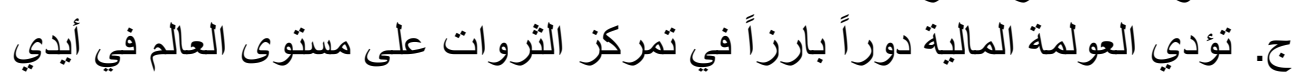

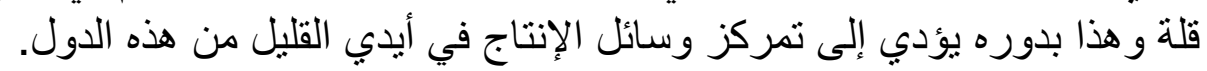

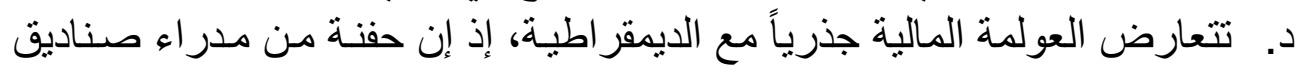

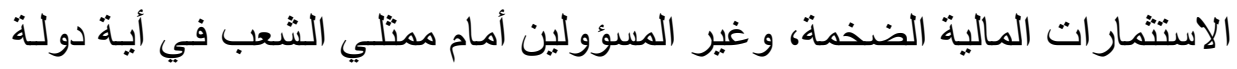
يتخذون وينفذون في لحظات قرار الات قات قد تدمر حياة الملايين من الناس.

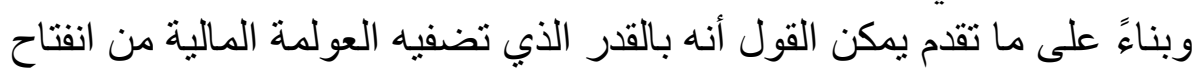

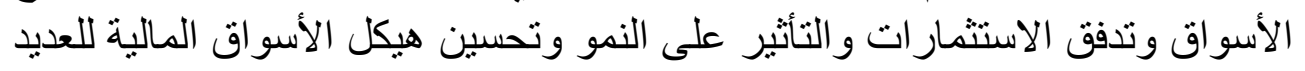

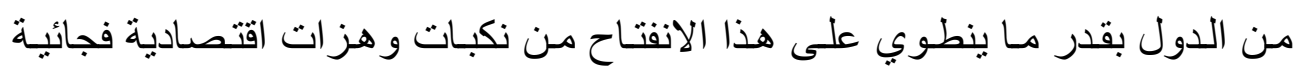

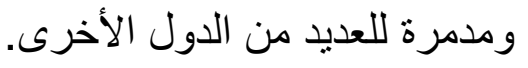

ا ـ ا العوامل المفسرة للعولمة المالية

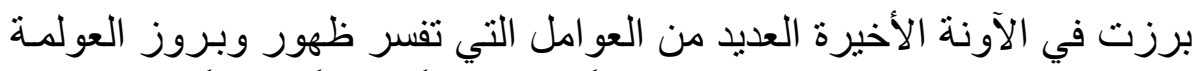

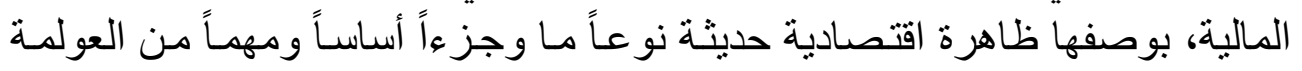

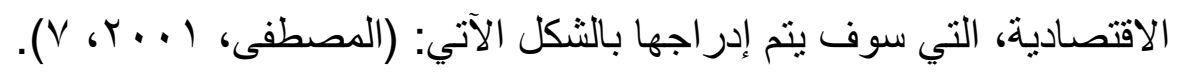




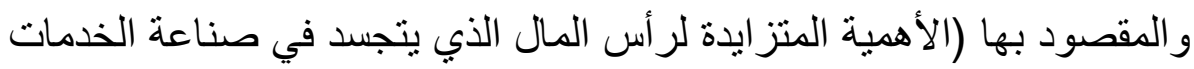

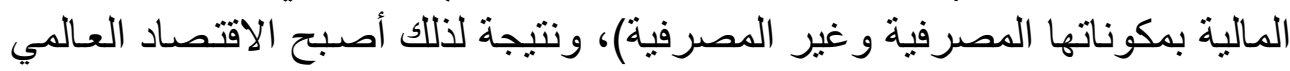

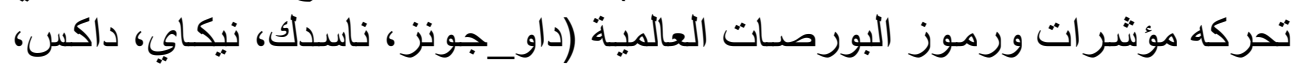

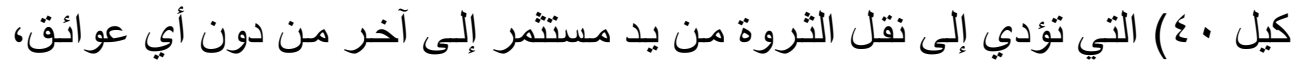

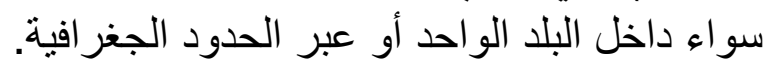

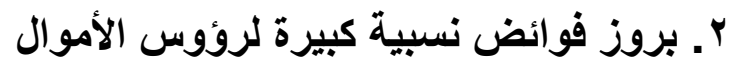

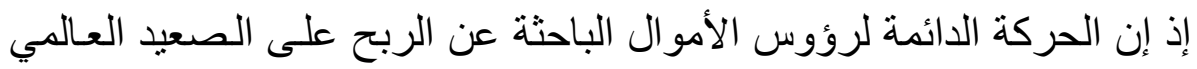

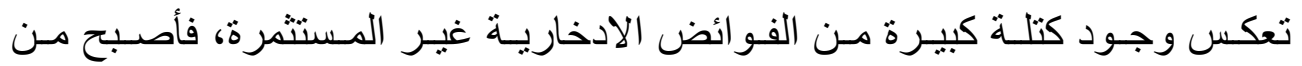

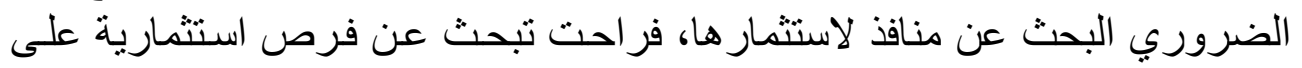

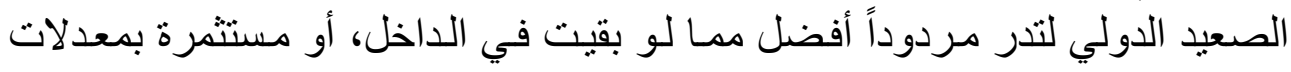

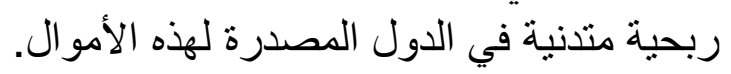

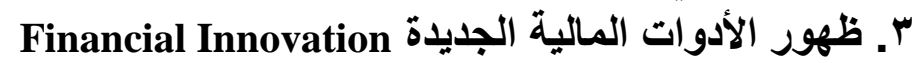
تكرست العولمة المالية بنمو الأدوات الماليدة المالية الجديدة التي استقطبت المستثمرين

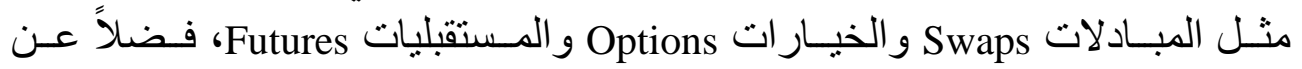
الأدوات التقليدية التي تتداول في الأسواق المالية و ولي الأسهم و السندات.

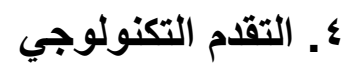

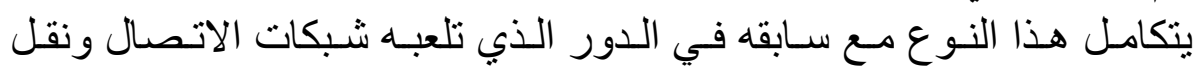

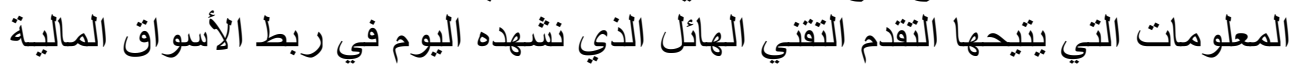

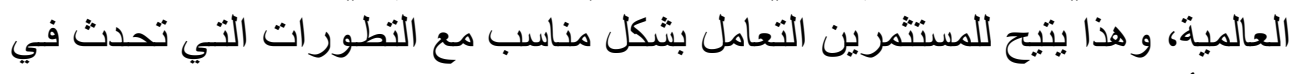
هذه الأسواق بصفة آنية وفوريّة.

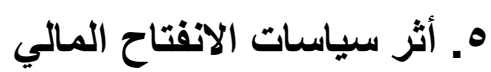

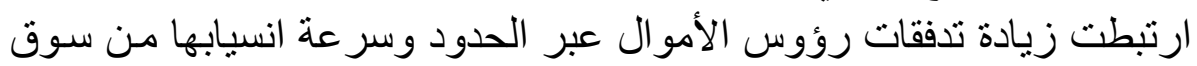

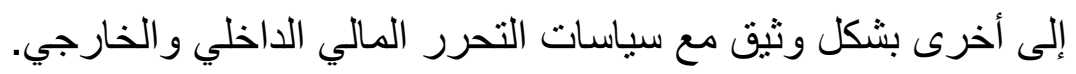

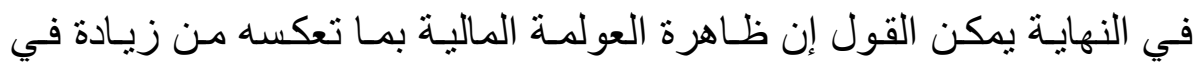

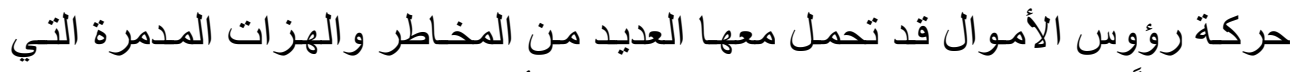

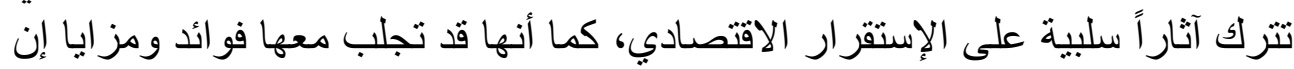

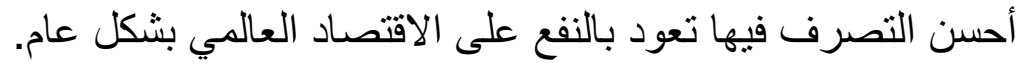

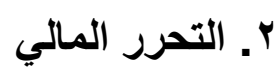

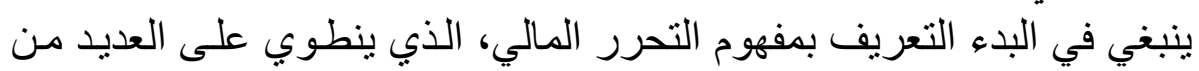

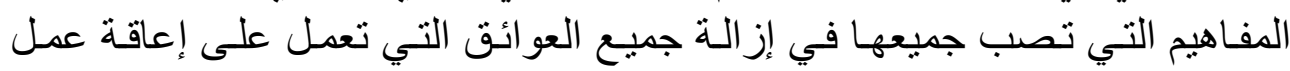
الأسو اق المالية في أرجاء العالم المختلفة. 


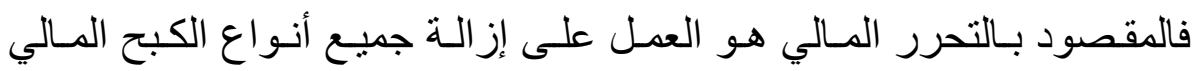

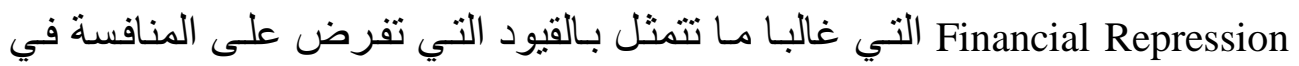

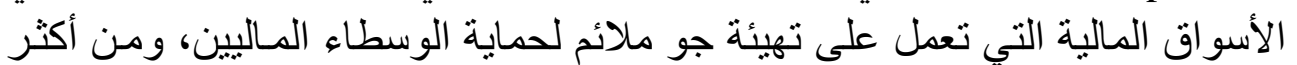

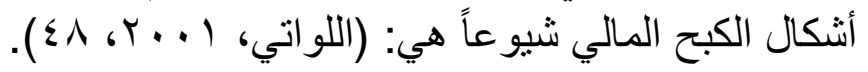

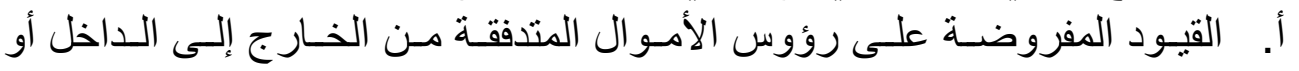

ب. القيود المفروضة على المنافسة الأجنبية في الأسواق المالية المحلية.

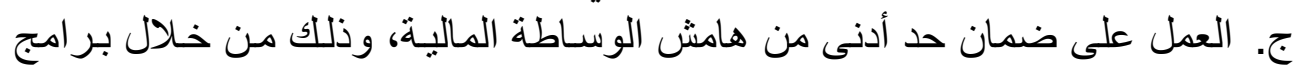

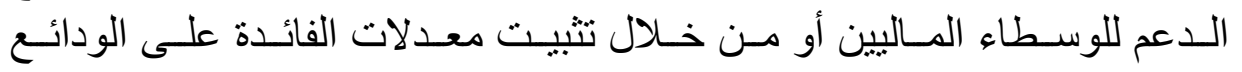

$$
\text { و القروض. }
$$

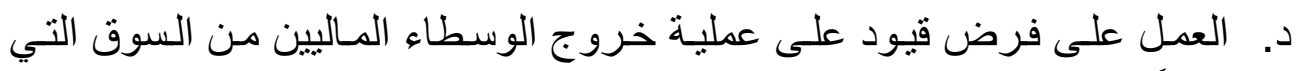

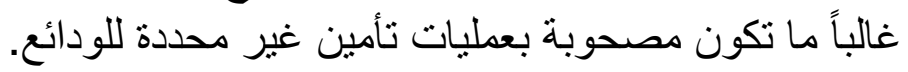

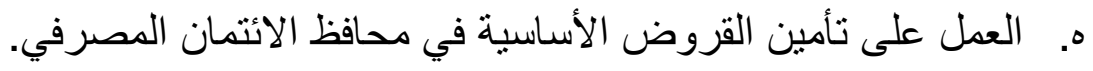

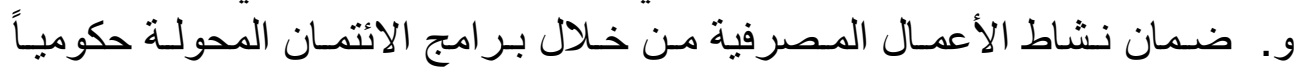
للقطاعات الأساسية.

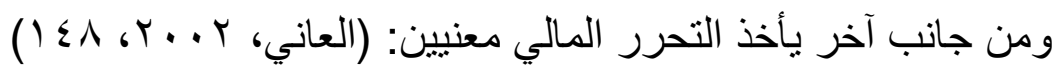

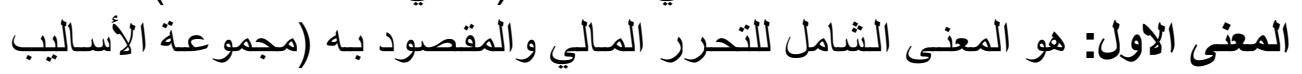

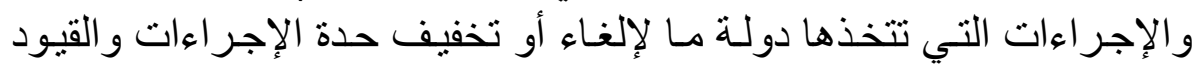

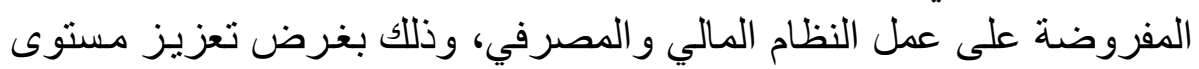

$$
\text { كفاءته و إصلاحه كلياً). }
$$

المعنى الثاني: ويتضمن العمل على تحرر عمليات السوق المالية من جميع القيود

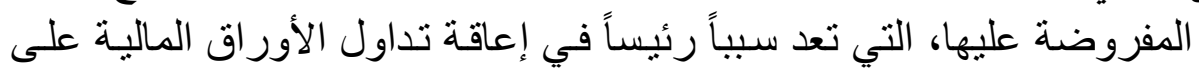
المستويين المحلي و الدولي. من خلال ما تقدم يمكن القول إن التحرر المالي يحمل معنى أوسع و أثنمل من مجرد كونه أداة لتأمين نزوح الرساميل بين الدول، و إنما يمتد ليشمل جميع العمليات

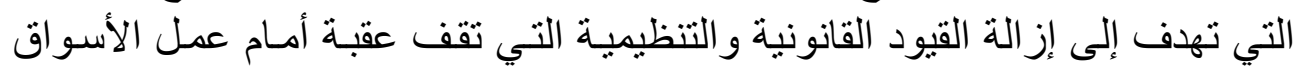
المالية وتطور ها في كل الدول.

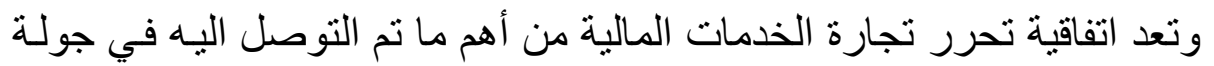

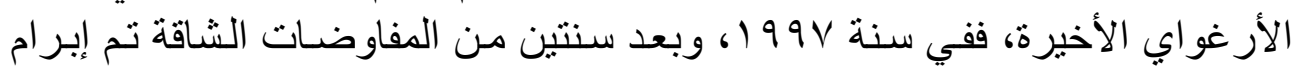

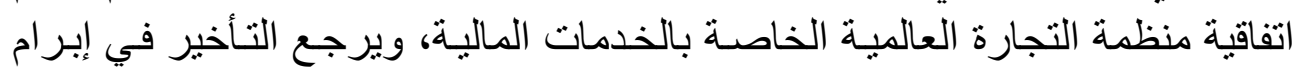

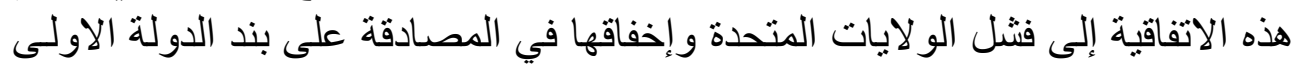
بالر عاية (MFN) فيما يخص الخدمات المالية. (Agosin, 1999, 67) 


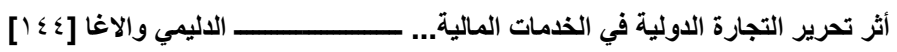

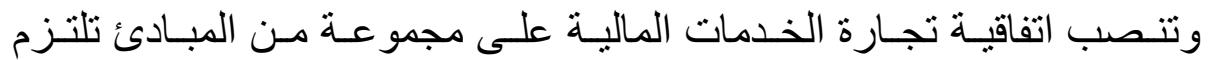

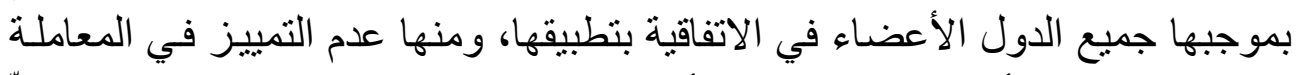

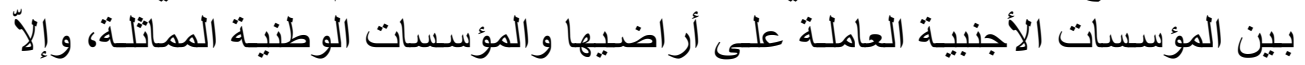

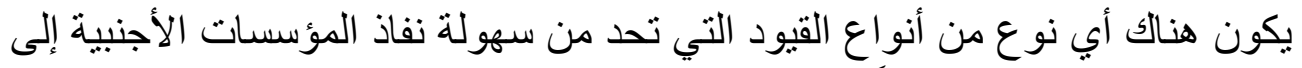
الأسواق المحلية، هذا فضلاً عن مبادئ أخرى و التز امات تنظم عن عمل الأسواق المالية.

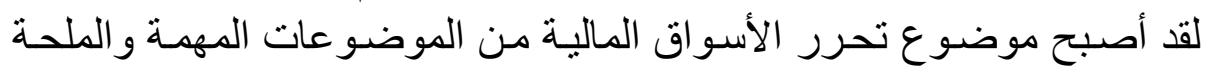

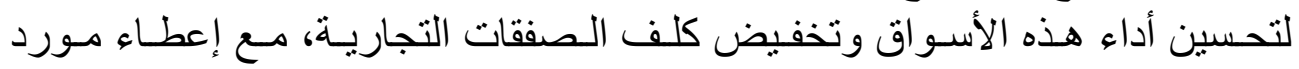

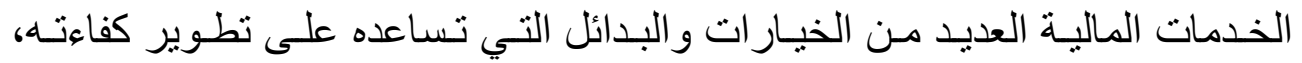

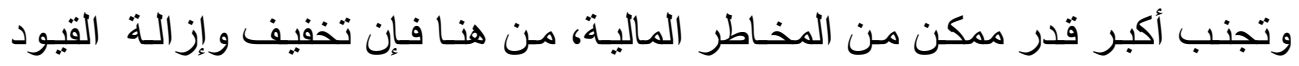

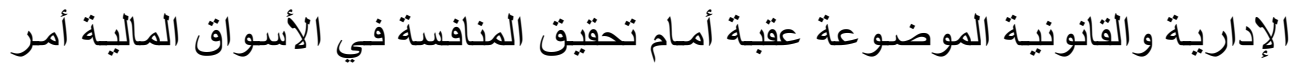

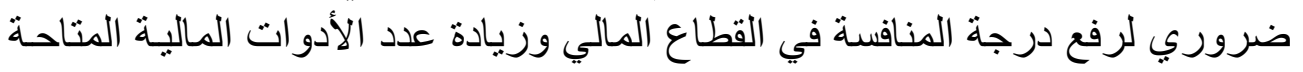
لموردي الخدمات المالية المحليين. (Mateo, 1989, 174)

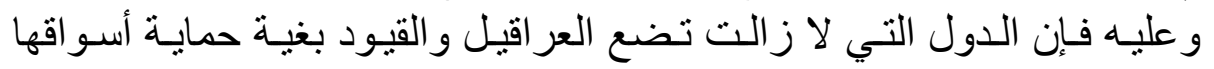

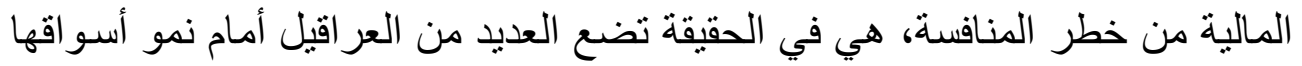

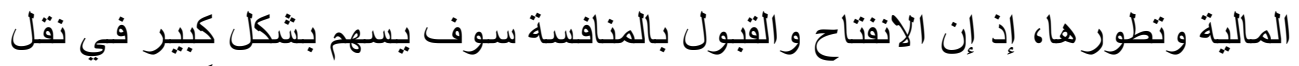

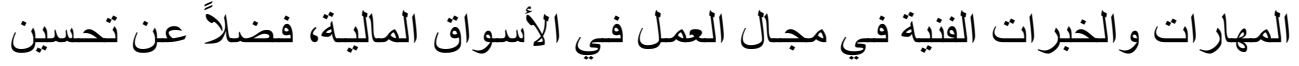

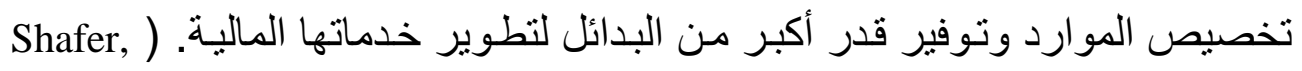

وفي دراسة أجر اها الدكتور جاسم المناعي المدير العام - رئيس مجلس إدارة

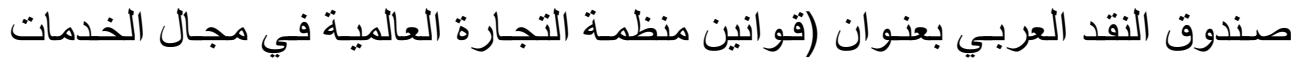

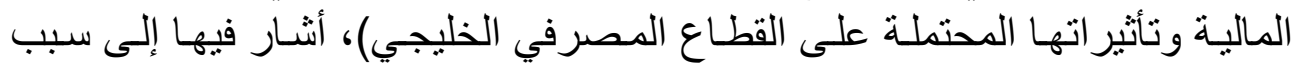

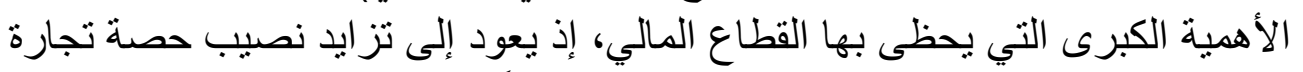

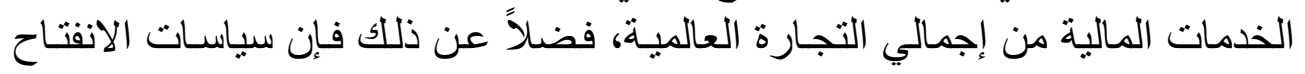

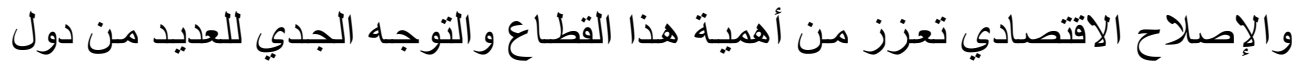

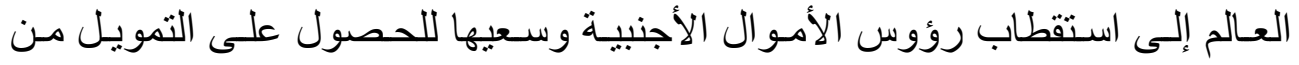

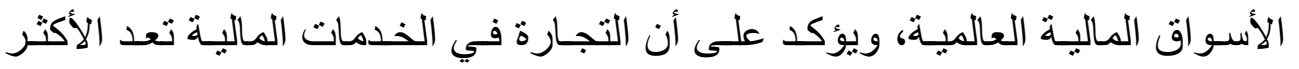

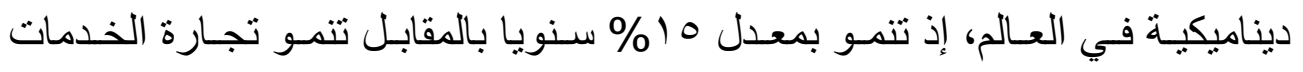

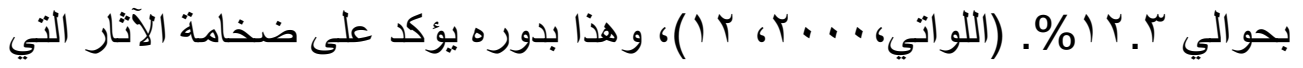

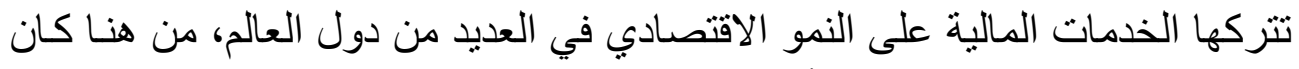

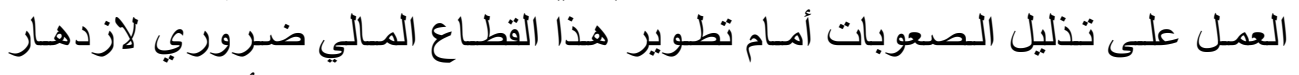

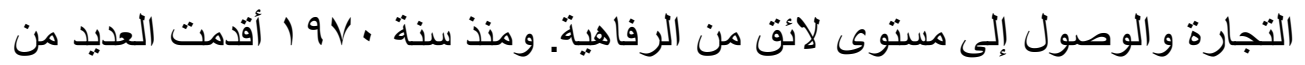

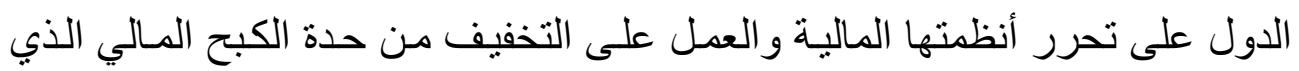

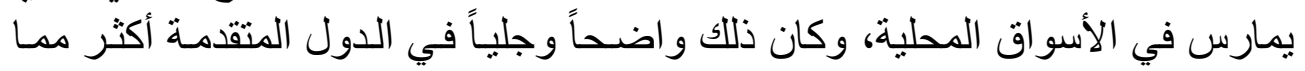


$(r \cdot)^{9} \cdot$ [0 [ [ [ ] كلية الادارة و الاقتصاد/جامعة الموصل

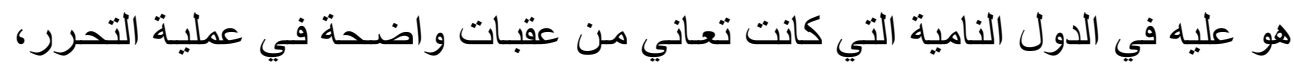

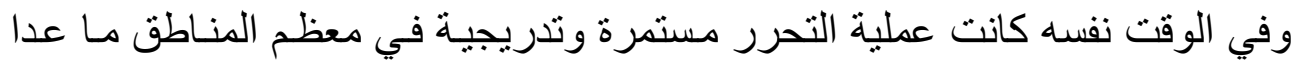

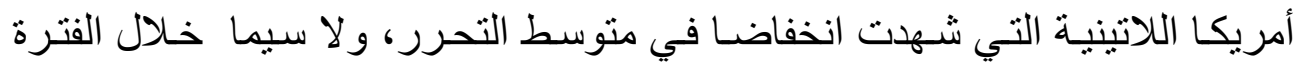

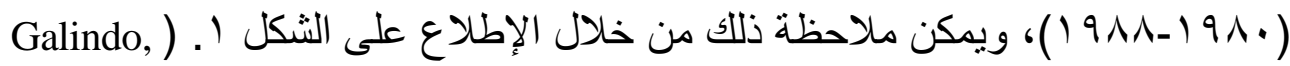

$(2002,2-3$

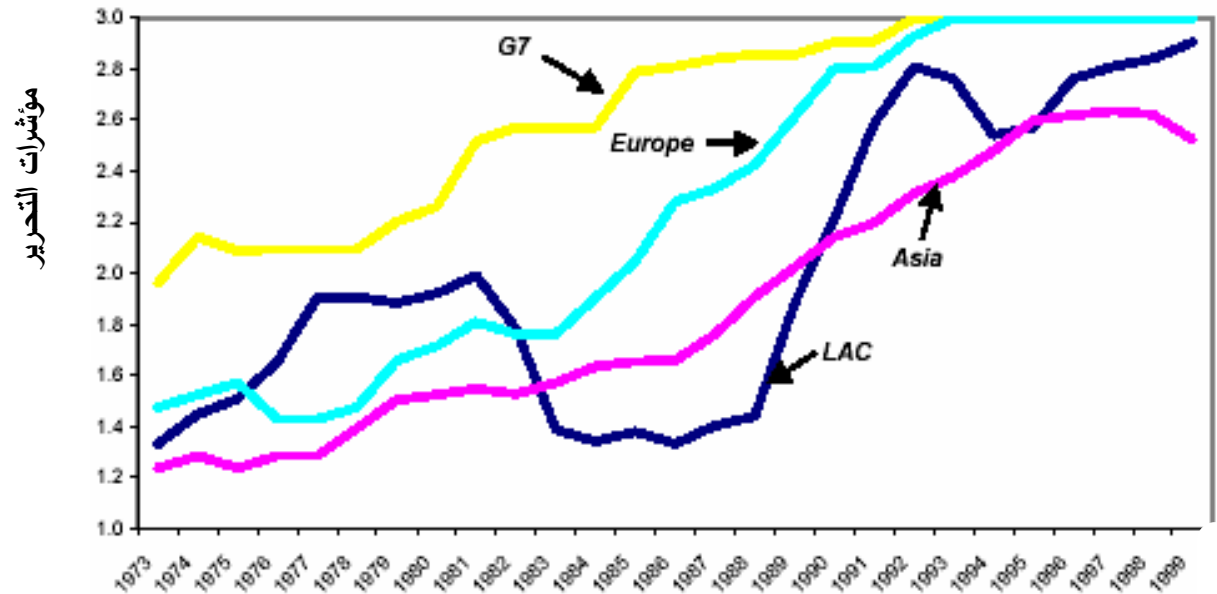

السنوات

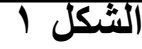

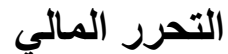

Source: Arturo Galindo (2002), Financial liberalization growth, World Bank.p.3

نلاحظ من الثكل البياني السابق أن مؤشرات التحرر المالي محصورة مـا بين

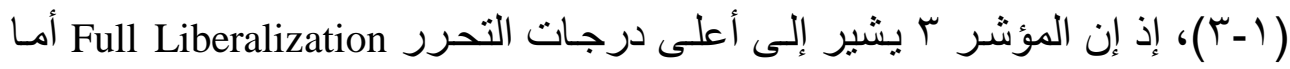

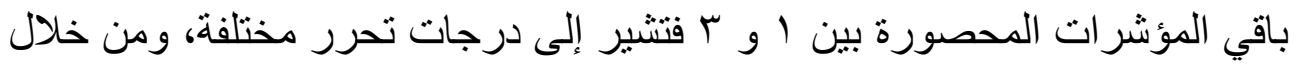

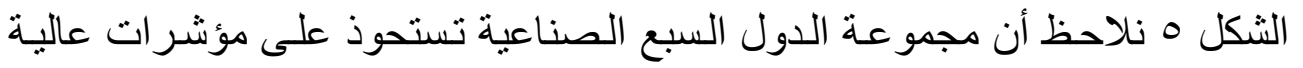

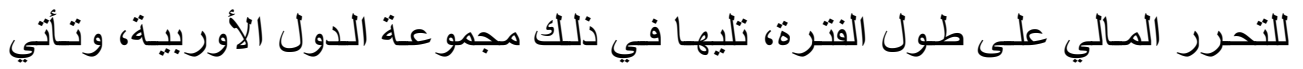

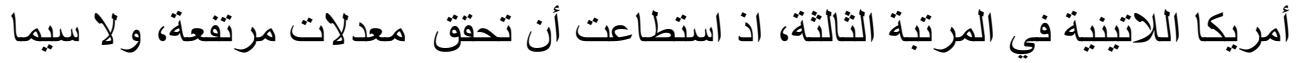

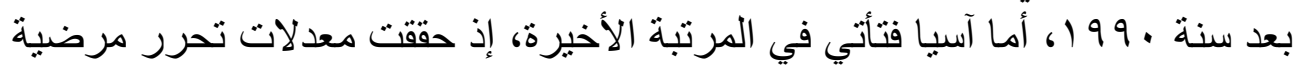

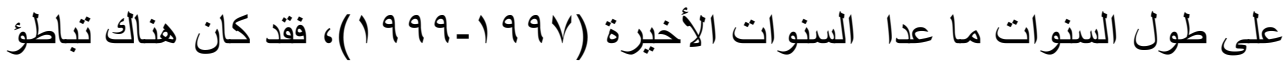
وتزاجع في معدلات التحرر. من هنـا يمكن القول إن سعي معظم الدول إلى تحرد

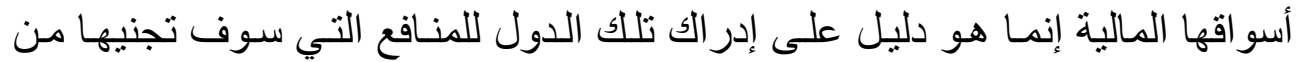

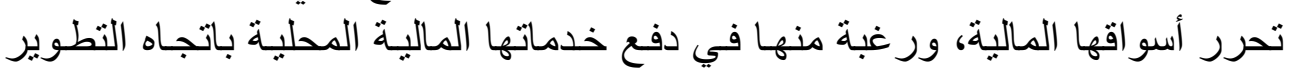

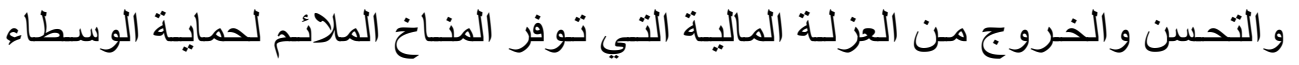
الماليين المحليين من مخاطر المنافسة الأجنبية. 
r - أهداف التحرر المالي

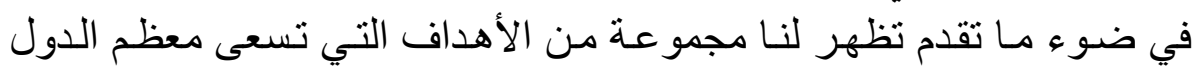

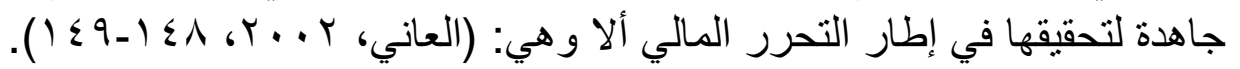

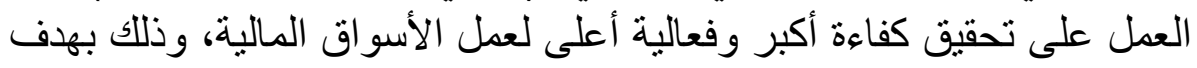

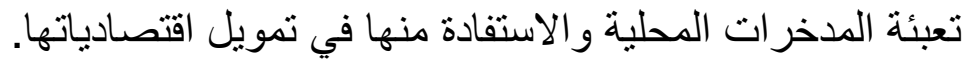

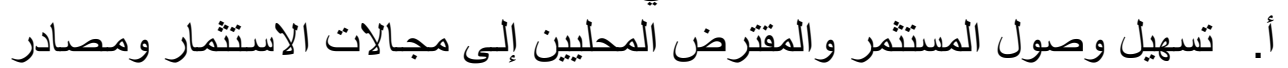

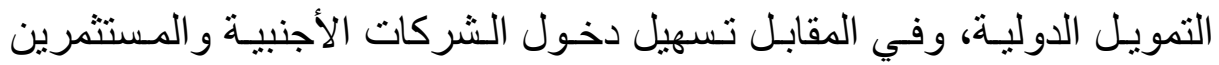

الأجانب في الأسواق المالية المحلية.

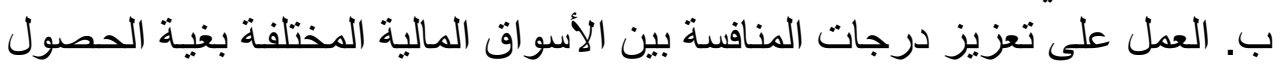
على أكبر قدر ممكن من رؤوس الأمو ال الدولية.

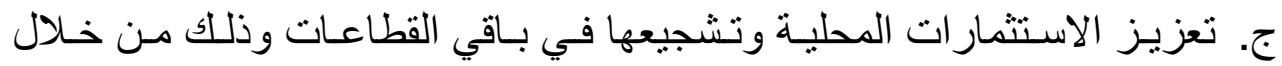

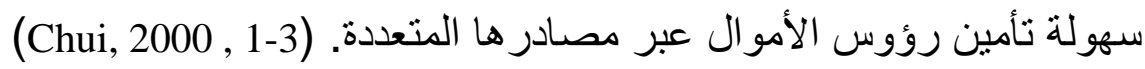

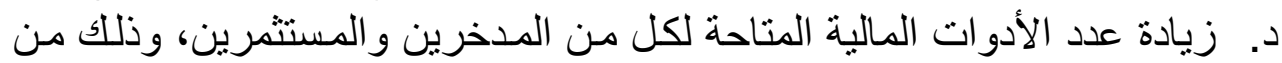

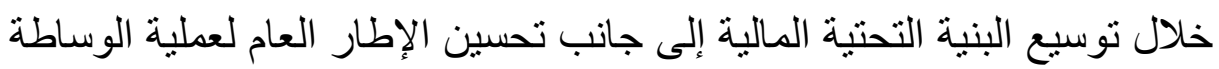

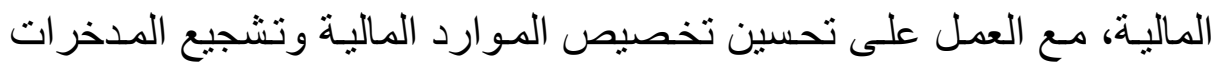

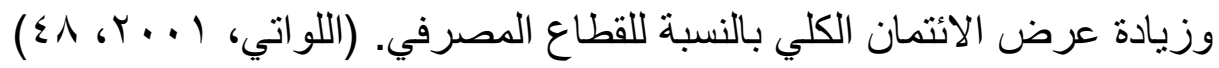

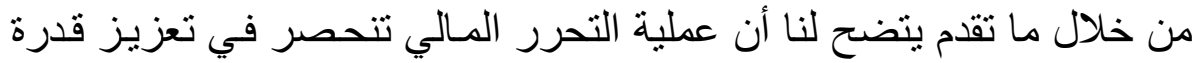

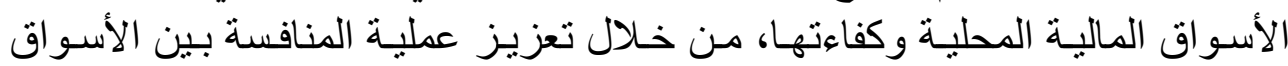

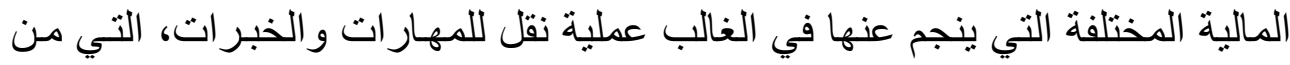
شأنها العمل على رفع كفاءة العمل في هذه الأسواق.

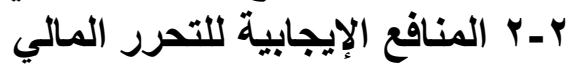

على الر غم ممـا ينطوي عليـه تحرر الأسـواق الماليـة مـن مخـاطر وتحديات

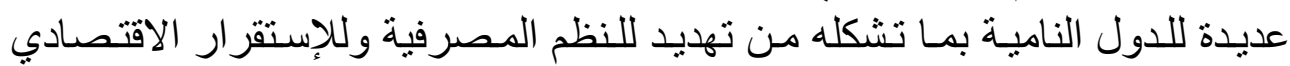
بوصفها نتيجة للتقلبات الفجائية التي تحدث في حركة دخول وخروج تلائه هذه الأمو ال من

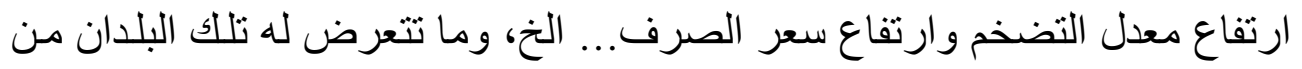
هجمات المضاربين وإلى إضعاف السيادة الوطنية في مجال السياسة المالية و النقديـة،

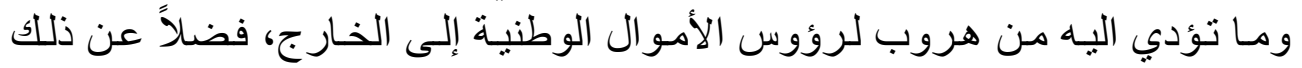
التهميش الذي تتعرض له هذه المصارف التهن الوطنية بوصفها نتيجة للمنافسة القوية التي

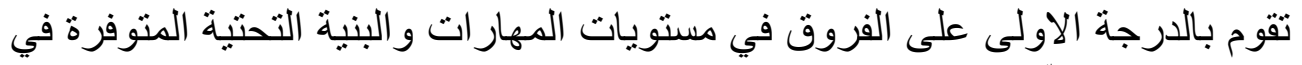

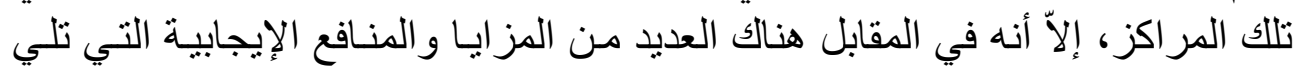

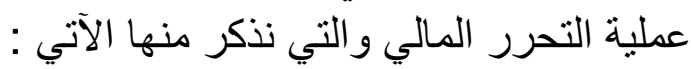
(Le Fort \& Budnevich, 1997, 39) (Jomo, 2001, 21-22) 
أ. تعمل على تعزيز المنافسة في الأسواق الماليـة مع تحسين كفاءة أداء الخدمات

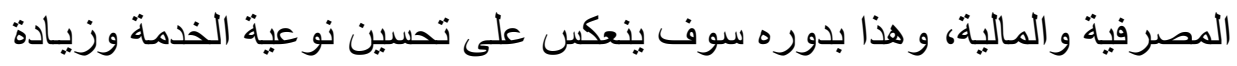

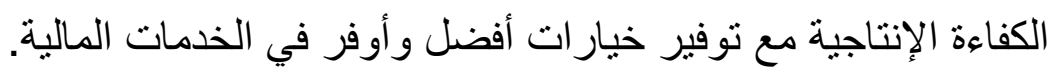

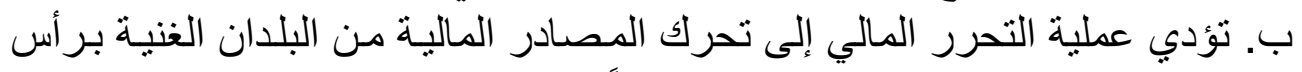

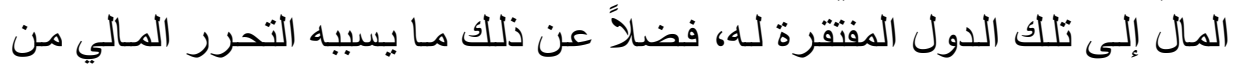

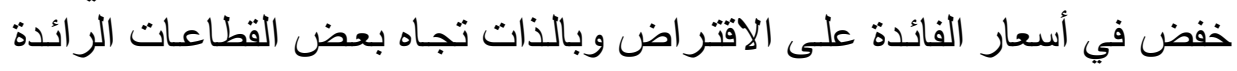

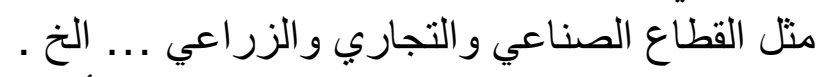

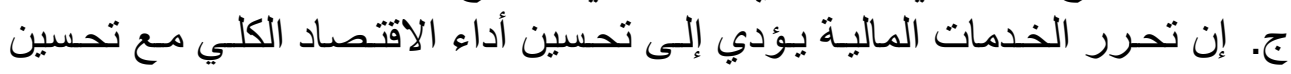

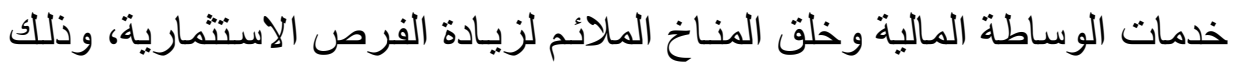

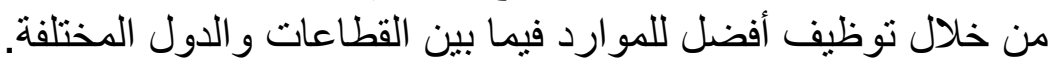

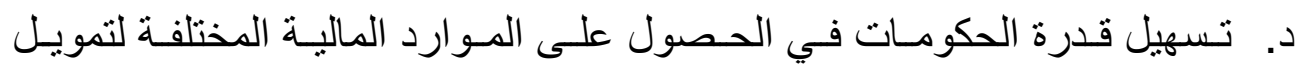

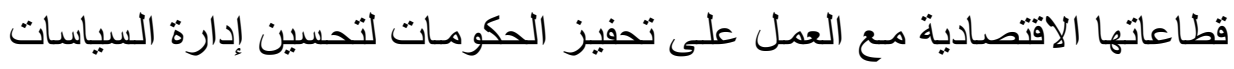

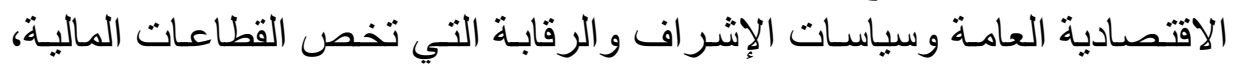

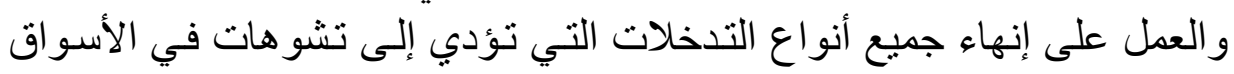

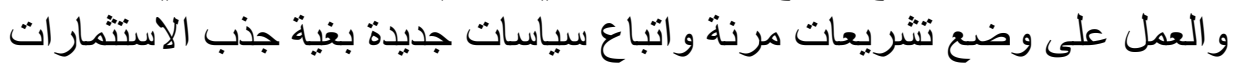

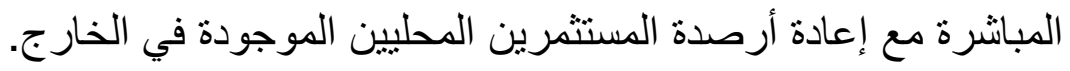

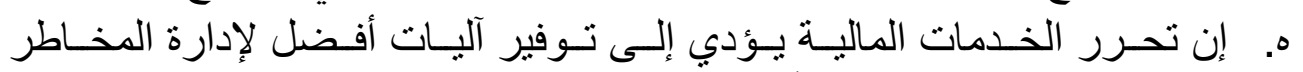

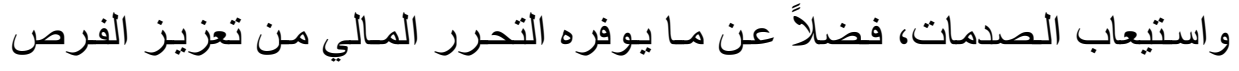

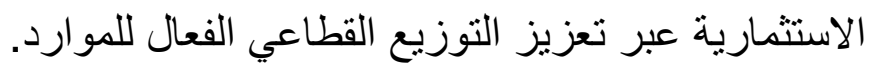

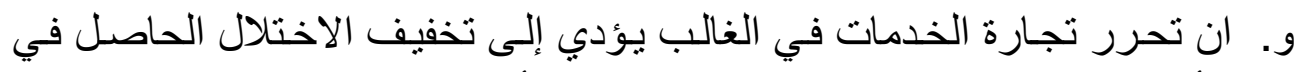

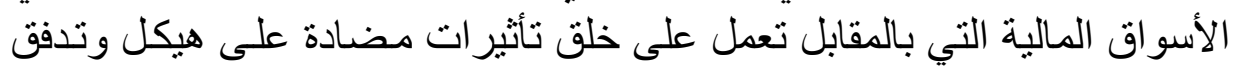

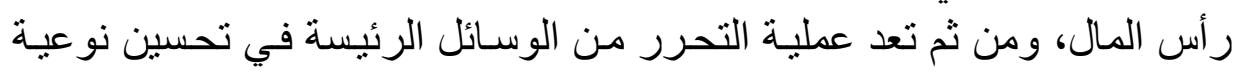

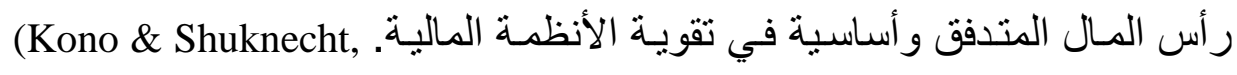

ز. بضاف إلى تلك الفو ائد عنصر أساسي وهو تحسين عمل WTO في آلية تسوية المناز عـات التي تـساعد بـدور ها في كبح مفهوم الحمايـة أو التـرويج للحمايـة.

(Hirano, 1999, 1)

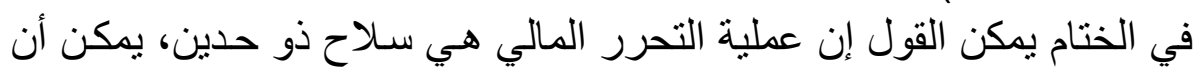

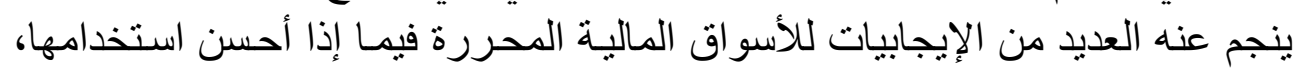

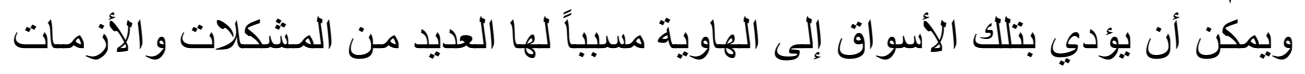

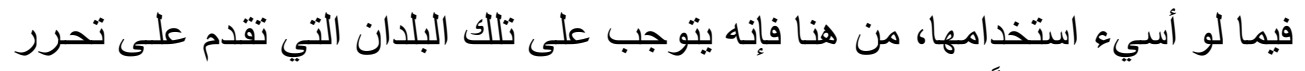

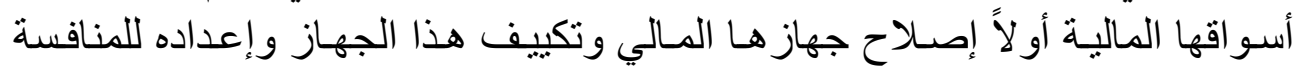




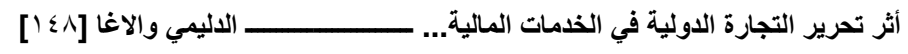

المستقبلية، ولكي يتمكن بشكل فعلي من الاستفادة من المنافسة و اكتساب الخبرات

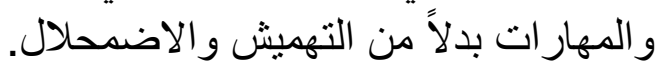

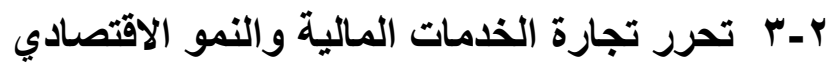

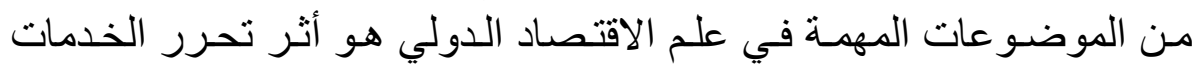

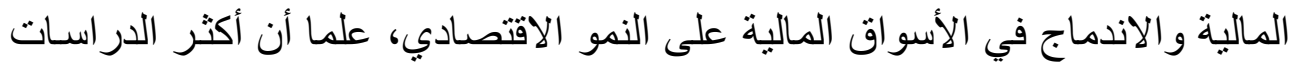

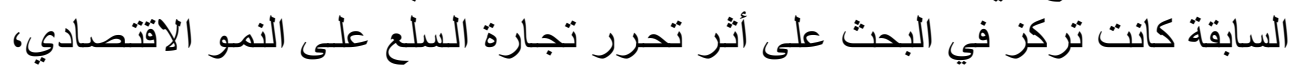

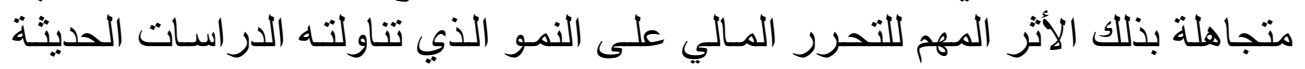
ومسن أبـرز تلك الدر اسـات التي تناولت تفسير علاقـة التحرر المـالي بـالنمو بشكل مكثف.

الاقتصادي هي: (Francois, 1999, 3-4)

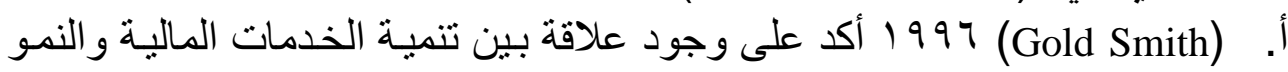
الاقتصادي.

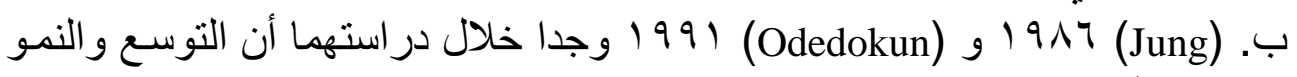
في الأسواق المالية له آثار مهمة على النمو في الدول النامية.

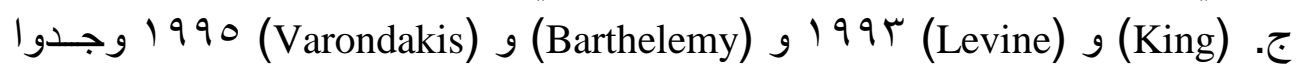

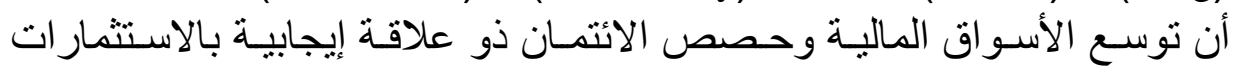
و الانتاجية و النمو الحقيقي.

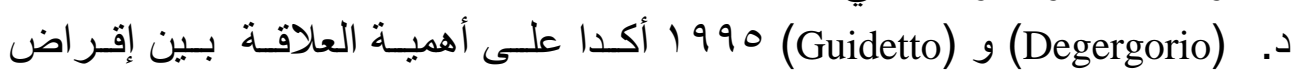
القطاع الخاص و النمو الاقتصادي.

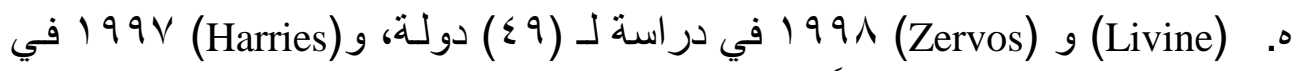

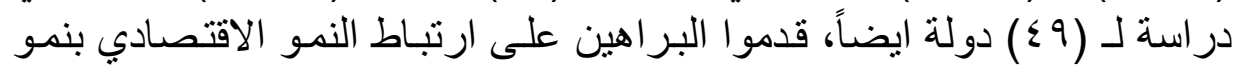
الأسواق المالية وتطور ها. دولة الفاء وفي ضوء الدر اسـات السابقة نلاحظ أن معظمها تجمع على النى الآثار الإيجابية لتطوير الخدمات المالية وتحرر ها في النمو الاقتصادي.

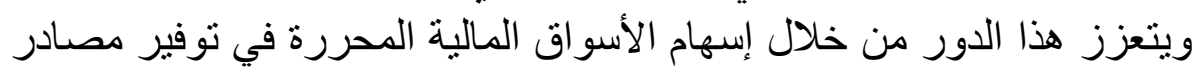

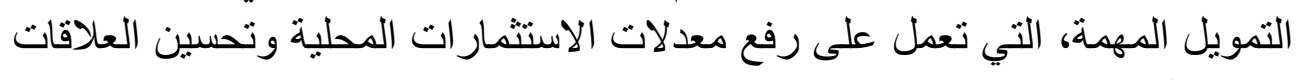
الإنتاجية (Tropeano, 2001, 18). من هنـا كـان للتدفق النقدي الذي يخلف عمليـة تحرر الأسـواق الماليـة دوره

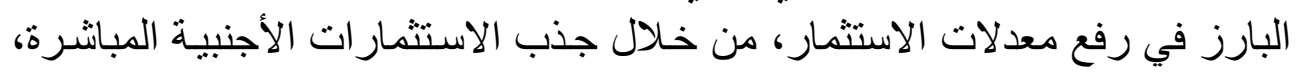

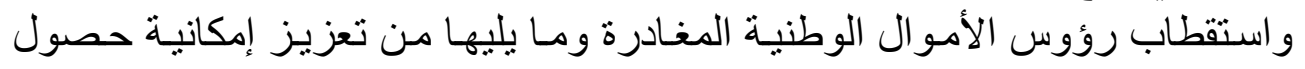

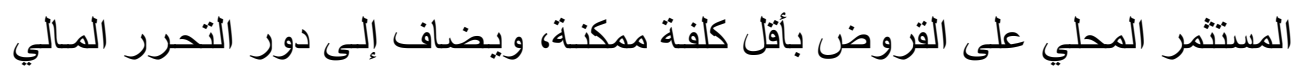

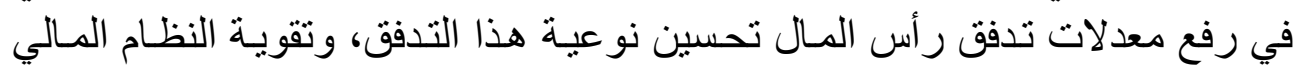

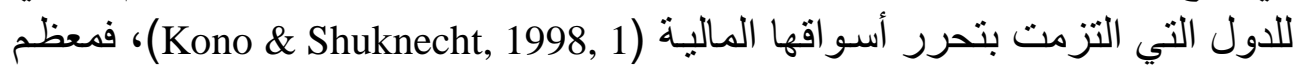


الصناعات تعتمد إلى حد بعيد على التمويل الخارجي الذي يوفره لها التحرر المـالي،

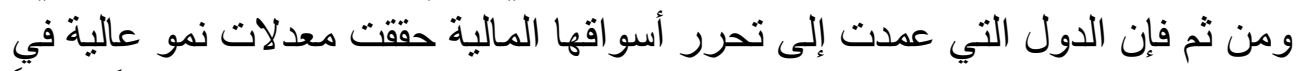

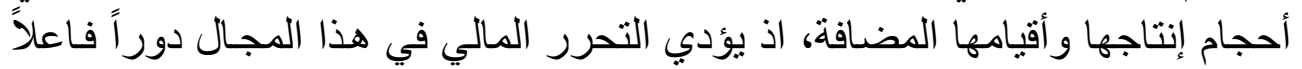

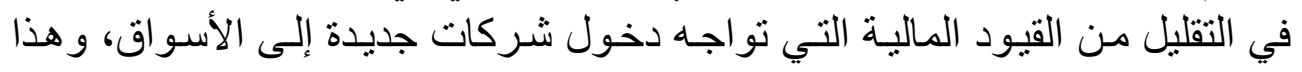

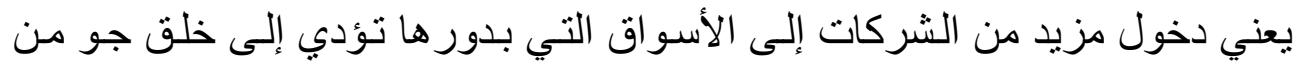

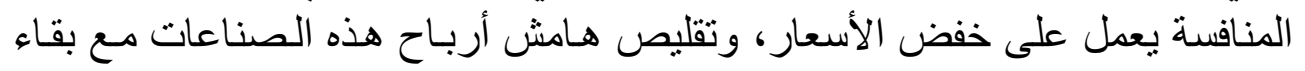

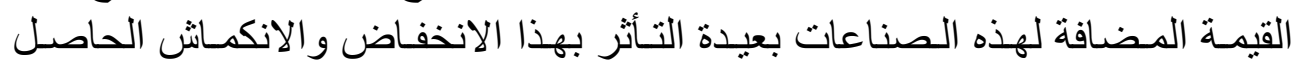
بالأرباح (Vlachos, 2002, 1-2) .

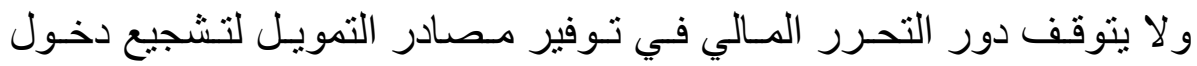

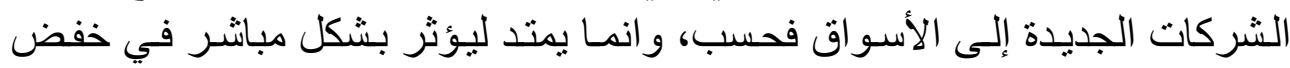

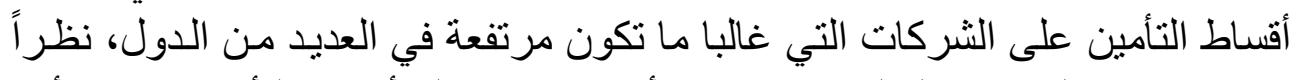

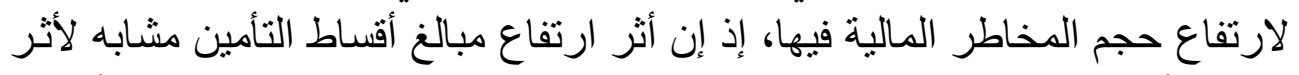

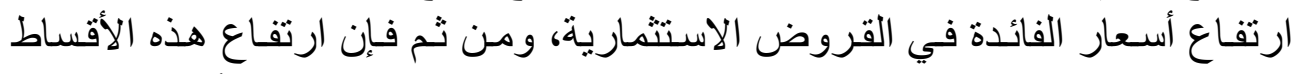

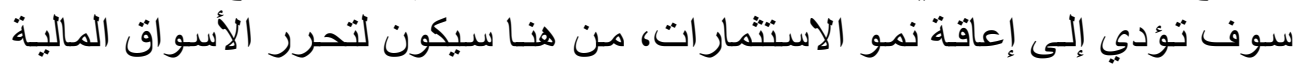

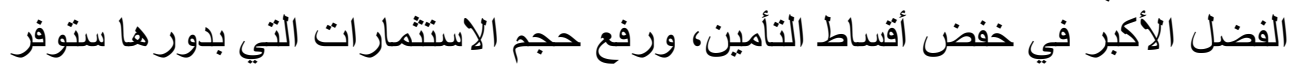

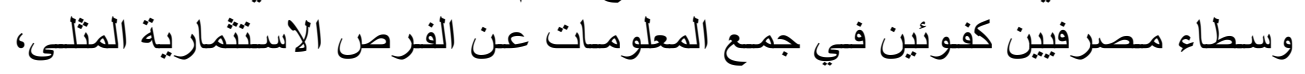

وارشاد المقترضين إلى مصادر الاستثمار الأكثر إنتاجية. (Harries, 1994, 38)

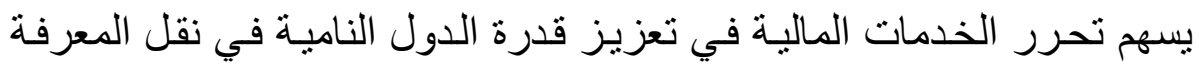

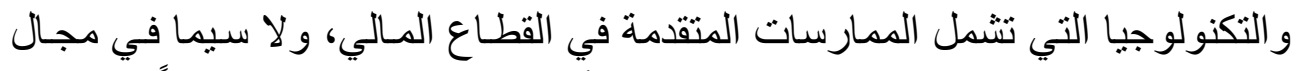

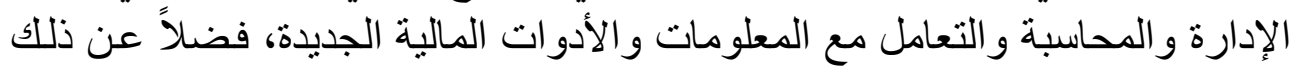

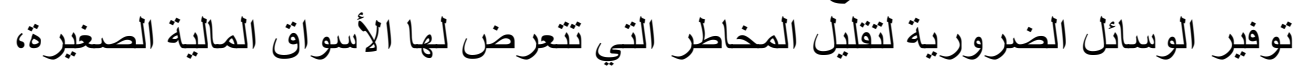

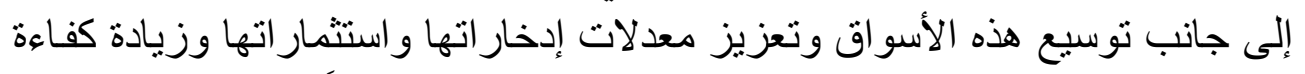

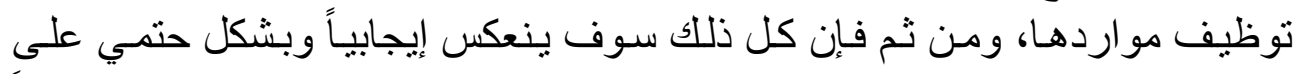

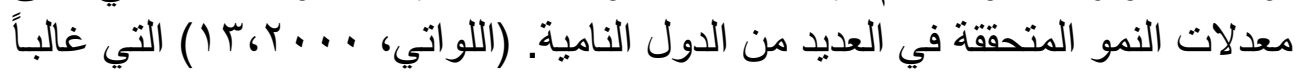

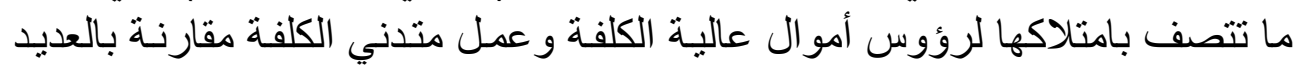

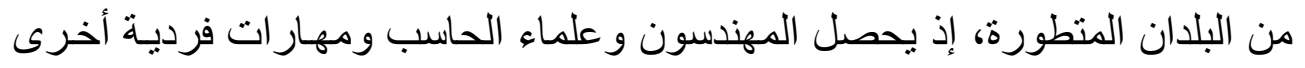

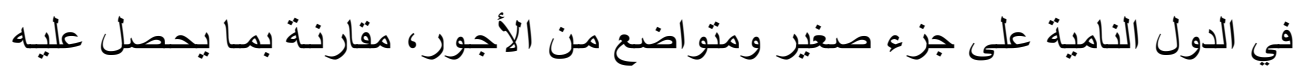

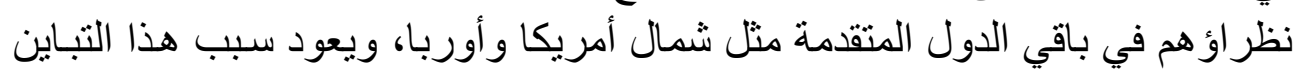

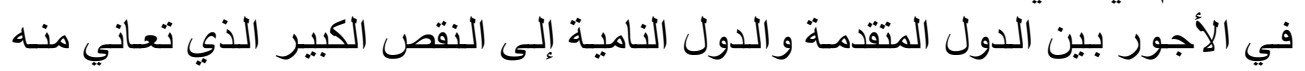

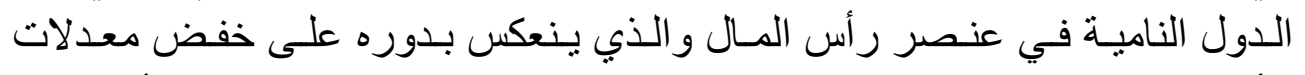

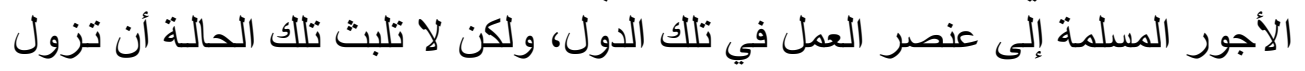

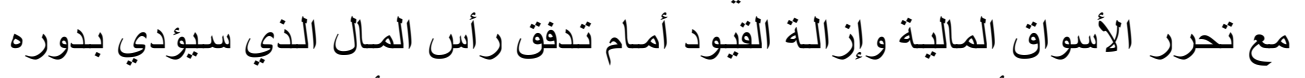
إلى مساو اة كلف رأس المال في جميع الدول التي حررت أسو اقها المالية، وسيقود 


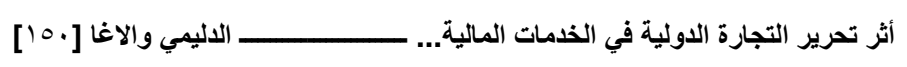

هذا التساوي في كلف رأس المال بين الدول إلى مساو اة كلف العمل في تلك الدول، ومن ثم سوف ينعكس ذللك على نمو معدلات الاستثمار المحلية التي بدور ها سوف تنعكس على رفع معدلات النمو الاقتصادي (Chui, 2000, 1).

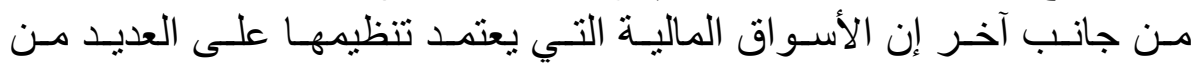

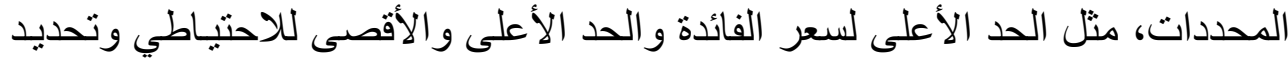

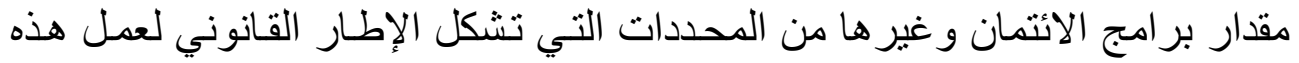

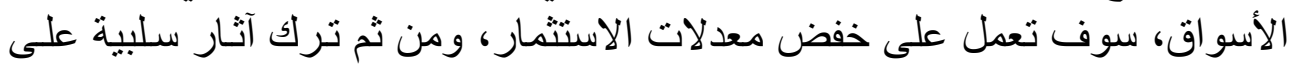

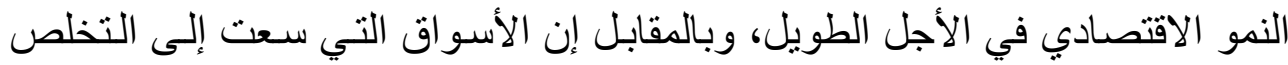

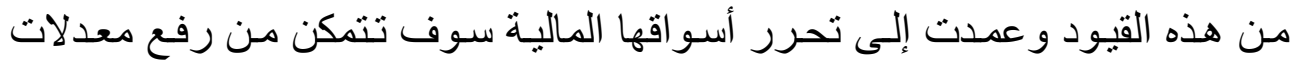

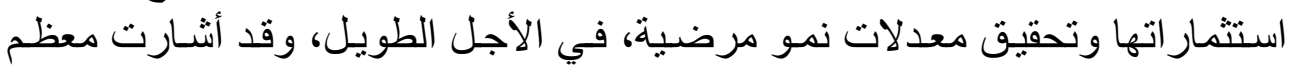

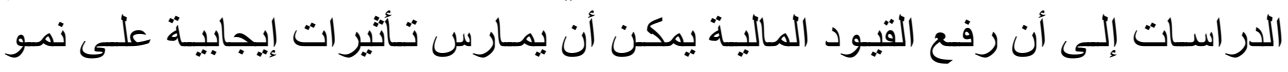

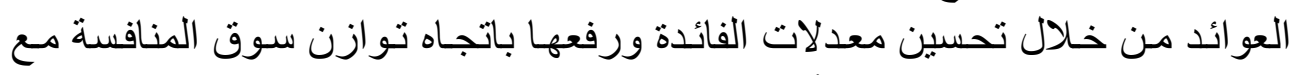

إعادة تخصيص الموارد بشكل أفضل (Galindo, 2002, 2-3).

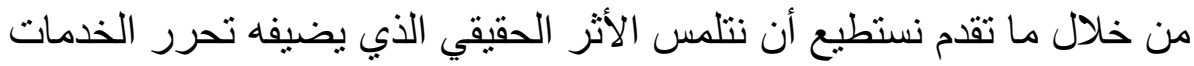

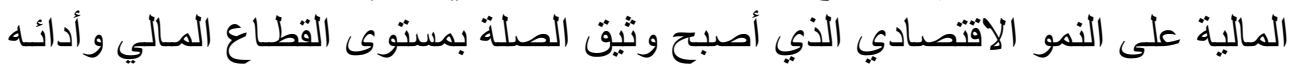

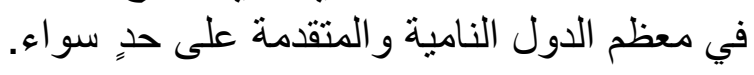

\section{r. بناء النموذج القياسي المستخدم في التقدير وتوصيفه}

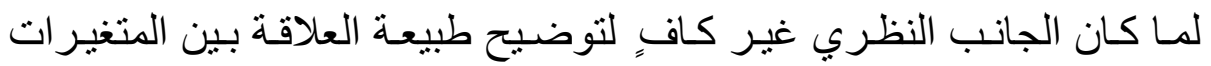

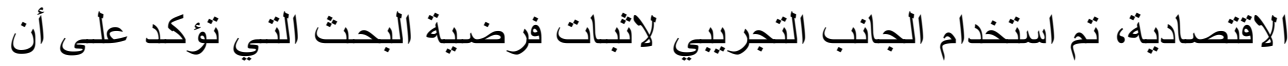
النمو الاقتصادي الذي يمثل المتغير المعتمد (المستجيب) يتأثر وبشكل إيجابي بتحرر التجارة الدولية في الخدمات المالية التي بدور ها تمثل المتغير المستقل.

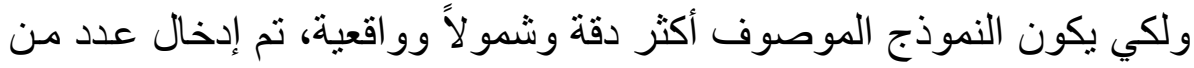

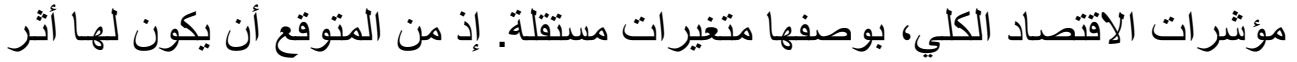

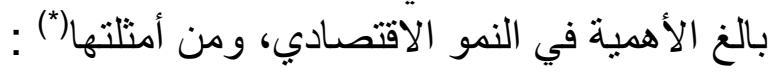

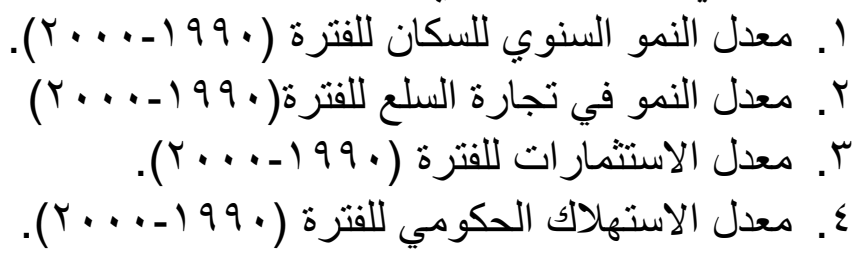

(*) جمعت المتغير ات المذكورة آنفا من قبل الباحث ، بالاعتماد على بيانات المصدر الآتية : - UNCTAD (2002), Hand Book of statistics, United Nation, New York and Geneva.

- UNCTAD (1996-1997), Hand Book of international Trade and development statistics, United Nation, New York and Geneva .

- United Nations (2001), Human Development Report, New York .

- United Nations (2002), Statistical Year Book, New York and Geneva. 


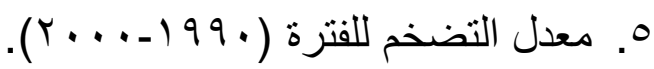

$$
\begin{aligned}
& \text { 7. . الإستقرار السياسي. }
\end{aligned}
$$

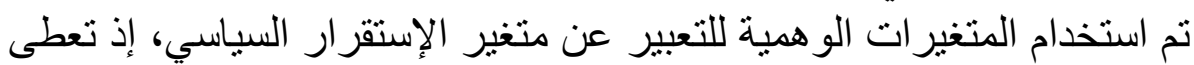

الدولة المستقرة سياسياً ( ()، وتعطى الدولة غير المستقرة سيآسيا (صفر).

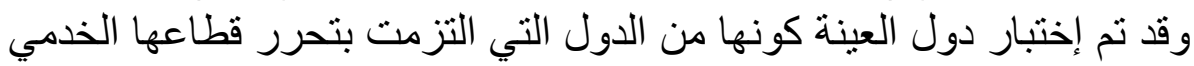

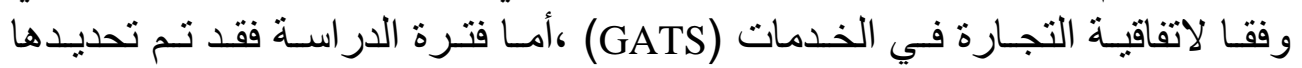
لاعتبارين أساسين وبالثكل الآتي:

أ. يجب أن تكون الفترة من الطول بحيث تسمح بإبراز أداء النمو في الأجل الطويل.

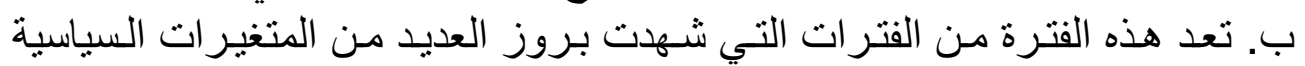

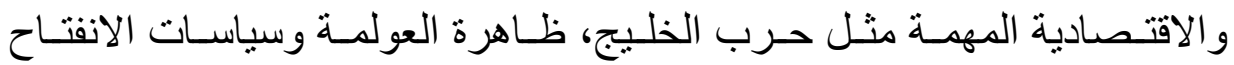

$$
\text { الاقتصادي التي أخذت تتوسع بشكل كبير خلال هذه الفترة . }
$$

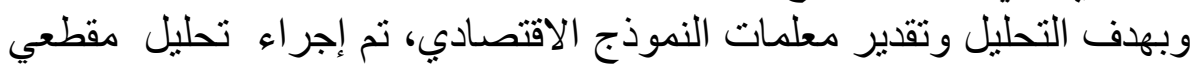

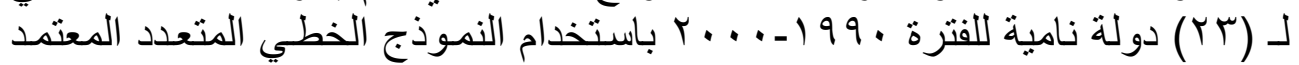

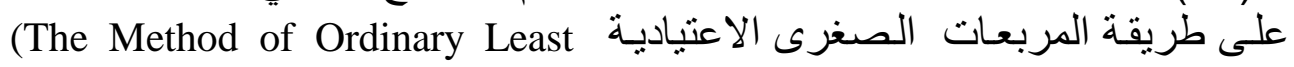

منية (OLS)

Squares)

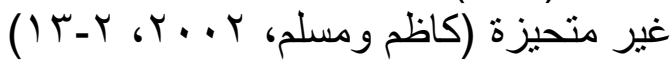

وبعد الانتهاء من توصيف واكاء النموذج القياسي المقدر يتم إعداد الثكل القياسي للنموذج وبالثكل الآتي:

PCGDP $_{\text {gr }}=b 1\left(\mathrm{PoP}_{\mathrm{gr}}\right)+\mathrm{b}_{2}(\mathrm{TRDgr})+\mathrm{b}_{3}(\mathrm{INVr})+\mathrm{b}_{4}(\mathrm{GOV})+\mathrm{b}_{5}(\mathrm{INFL})+\mathrm{b}_{6}(\mathrm{POLS})+$

\begin{tabular}{|c|c|}
\hline 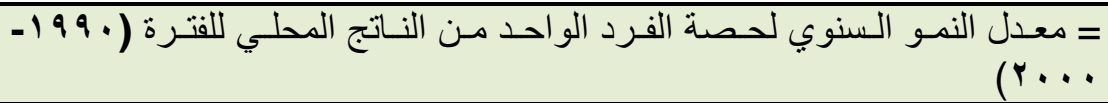 & PCGDP $_{g} \cdot 1$ \\
\hline = معدل النمو السنوي للسكان للفترة ( •99 ( - . . ץ) & $\mathrm{PoP}_{\mathrm{gr}} \cdot \mathrm{r}$ \\
\hline 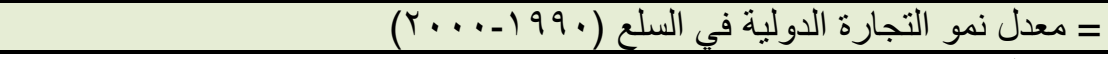 & TRDgr. . \\
\hline 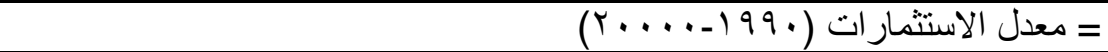 & $\operatorname{INVr} . \varepsilon$ \\
\hline 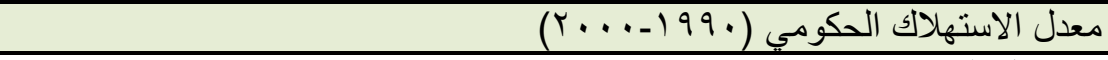 & GOV . ${ }^{\circ}$ \\
\hline 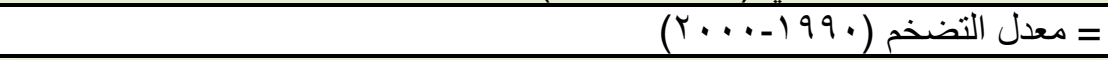 & INFL . 7 \\
\hline = الإستقرار السياسي & POLS.V \\
\hline = مؤشر الانفتاح في الخدمات المالية & FINC.$\wedge$ \\
\hline
\end{tabular}
$\mathrm{b}_{7}$ (FINC)

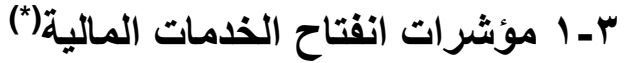

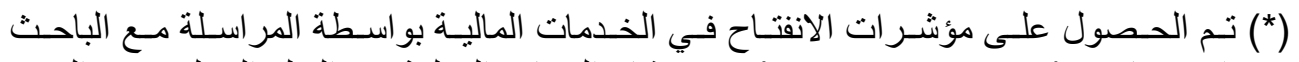

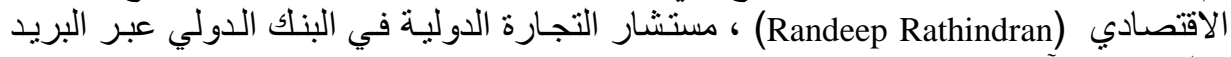




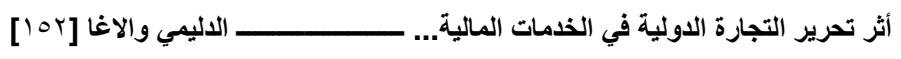

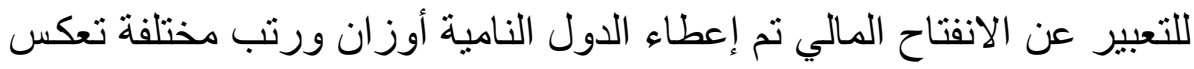

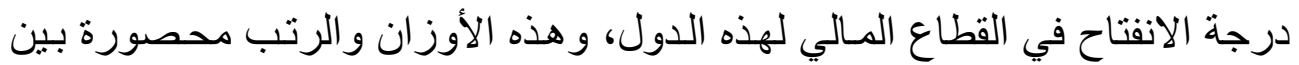

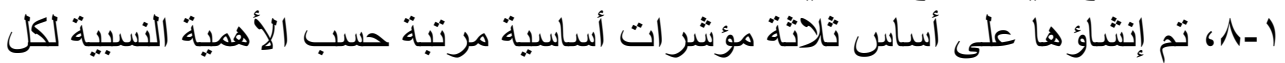

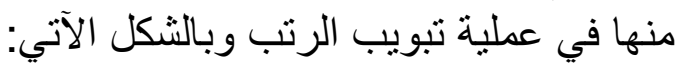
المؤشر الأول: هيكل سوق الخدمات المالية (منافسة، احتكار)

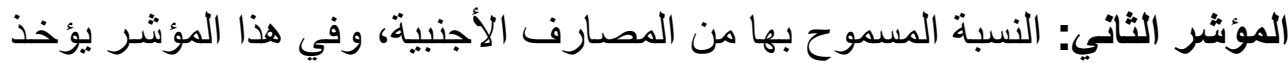

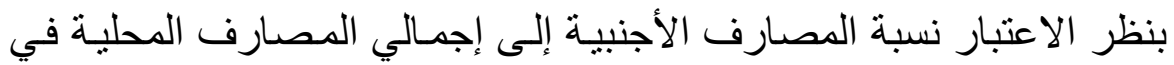
كل دولة، فعلى سبيل المثال يعدّ القطاع المالي في دولة الألة ما أكثر انفتاحاً عندما

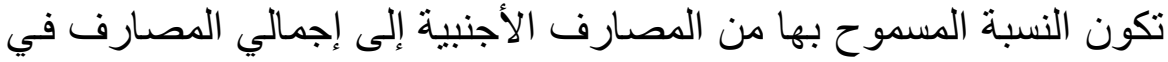

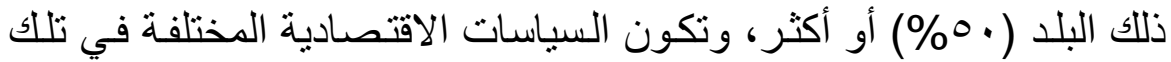
الدول هي المسؤولة عن تحديد هذه النسبة.

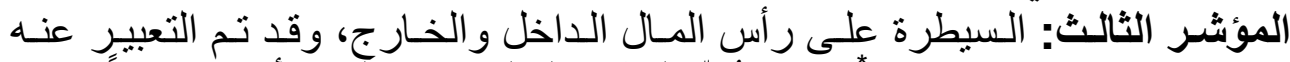

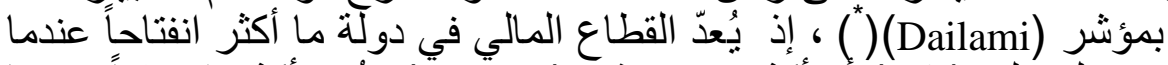

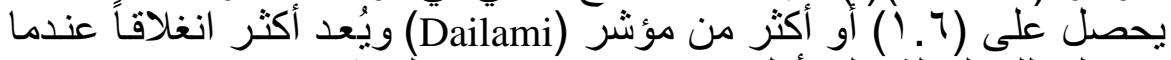

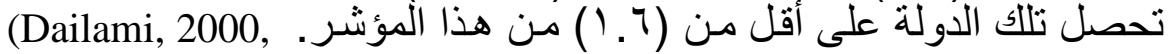

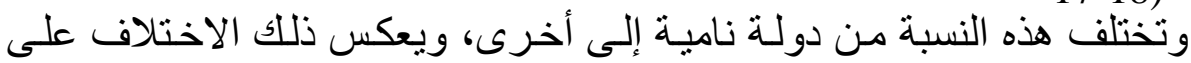

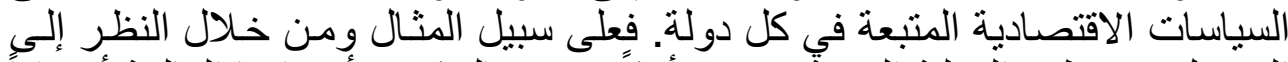

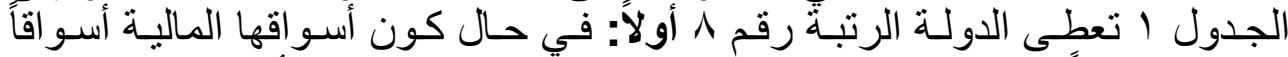

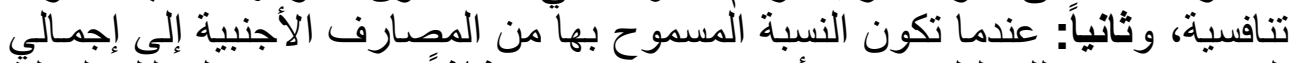

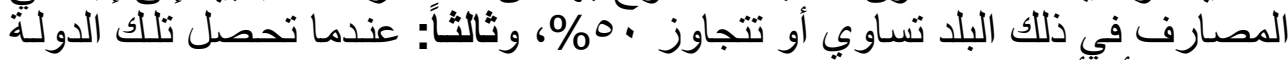
على 7.7 أو أكثر من مؤشر (Dailami)

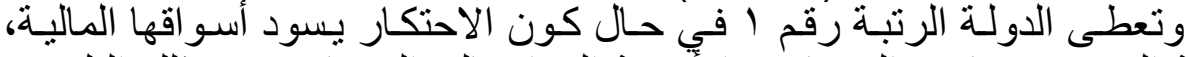

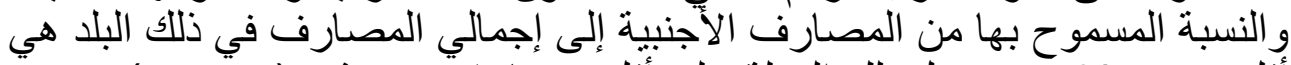

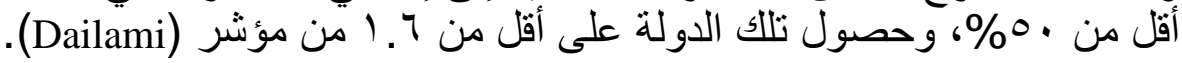

\begin{tabular}{|c|c|c|c|}
\hline \multicolumn{4}{|c|}{ مؤشر ات الانفتاح في القطاع المالي } \\
\hline السؤشرُ على رأس المال & النسبة المسموح بهارجية من & هيكل السوق & الرتبة \\
\hline $1.7 \leq$ & $\%^{0} \cdot \leq$ & منافسة & $\Lambda$ \\
\hline
\end{tabular}

E-mail:( rrathindran@wordbank.org ), (randeep@wam.umd.edu )

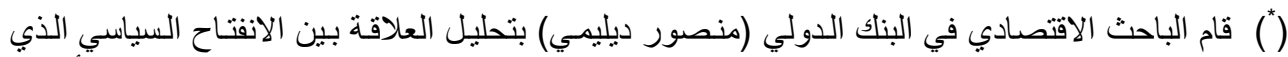

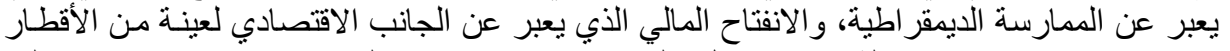

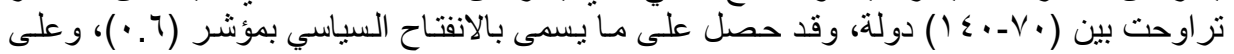

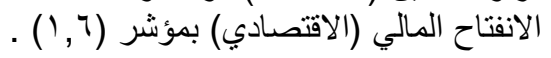




\begin{tabular}{|c|c|c|c|}
\hline $1.7>$ & $\% 0 \cdot \leq$ & منافسة & $\mathrm{V}$ \\
\hline $1.7 \leq$ & $\% 0 \cdot>$ & منافسة & 7 \\
\hline $1.7>$ & $\% 0 \cdot>$ & منافسة & 0 \\
\hline $1.7 \leq$ & $\% \circ \cdot \leq$ & احتكار & $\varepsilon$ \\
\hline $1.7>$ & $\% 0 \cdot \leq$ & احتكار & $r$ \\
\hline $1.7 \leq$ & $\% 0 \cdot>$ & احتكار & $r$ \\
\hline $1.7>$ & $\% 0 \cdot>$ & احتكار & 1 \\
\hline
\end{tabular}

Source: Aditya Mattoo (2001), (Measuring services Trade liberalization and its Impact on Economic Growth, World Bank, p27

\section{تقدير وتحليل أثر الانفتاح في الخدمات الماليـة على معدل النمو السنوي r-V} لحصة القرد الواحد من الناتج المحلي التئي

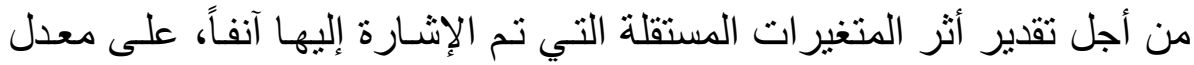

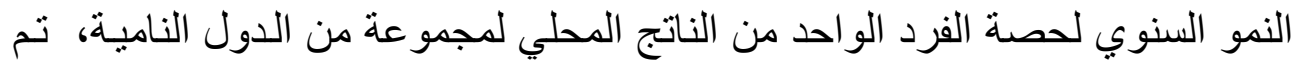
استخدام الصيغة الخطية التي أعطت النتائج آلاتية: PCGDP $_{\mathrm{gr}}=3.197-1.363 \mathrm{PoP}_{\mathrm{gr}}+0.112 \mathrm{INVr}-0.141 \mathrm{COV}+0.183 \mathrm{FINC}$
$\mathrm{t}=$
(2.393) (4.722)
(3.034)
(2.475)
$\mathrm{R}^{2}=0.69$ $\mathrm{F}=9.998$
D. $\mathrm{W}=2.501$

تثير القوة التفسيرية للنموذج المقدر إلى أن 79\% من التغير ات الحاصلة في

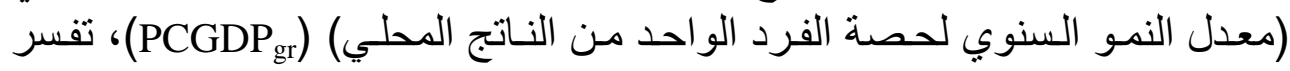

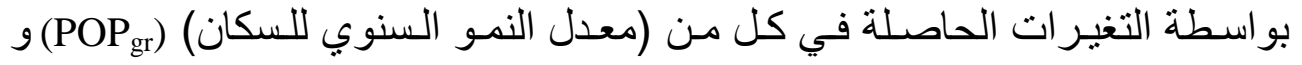

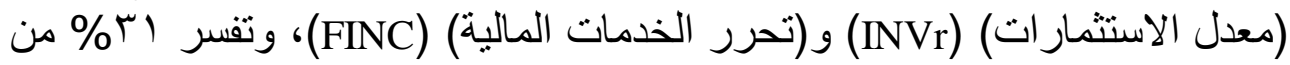

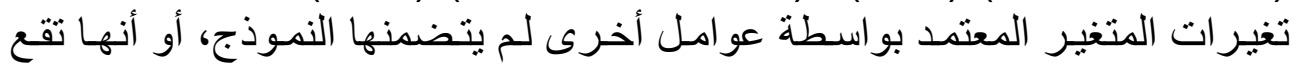
ضمن مفهوم المتغير العشو ائي. ولما تم إختبار مدى قالبلية المتغير ات المستقلة على تفسير التغير ات في المتغير

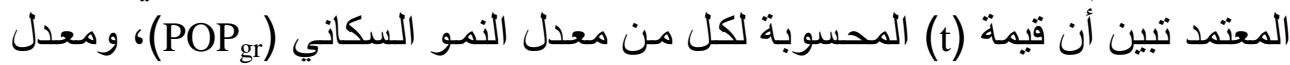

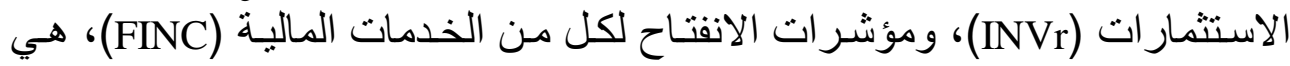

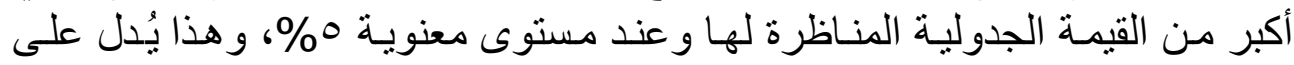

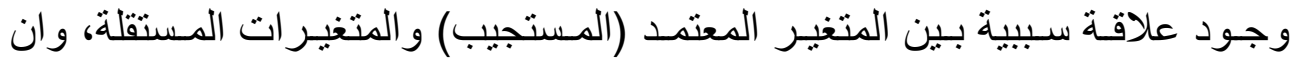

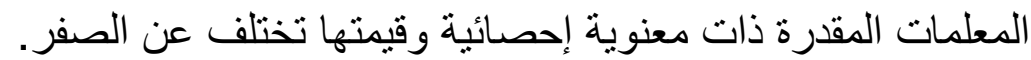

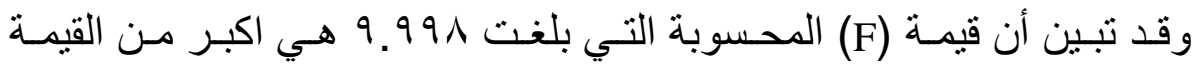

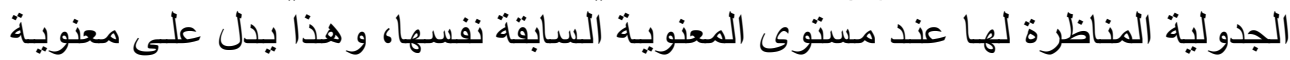
العلاقة الخطية بين المتغير ات المستقلة والمتغير المعتمد. وبلغت قيمـة دربن واطسن 


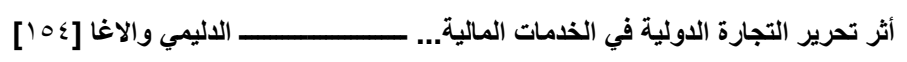

(D-W)

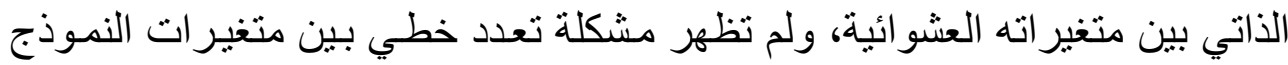

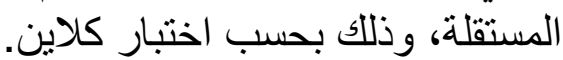

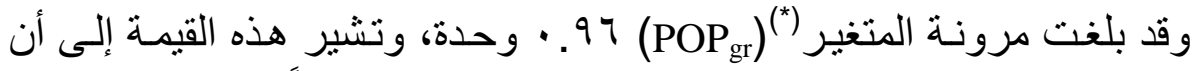

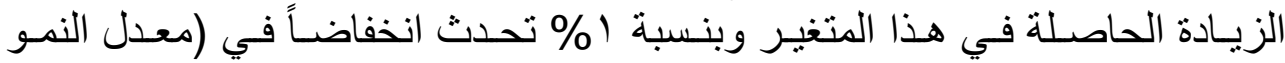

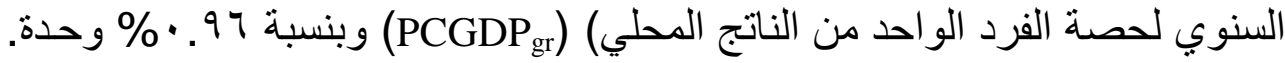

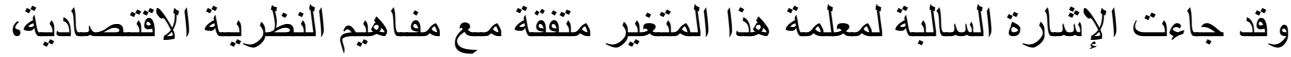

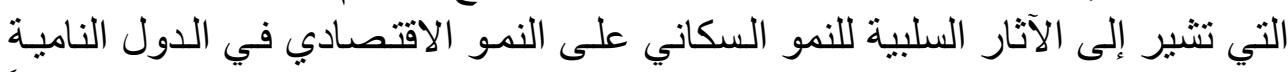

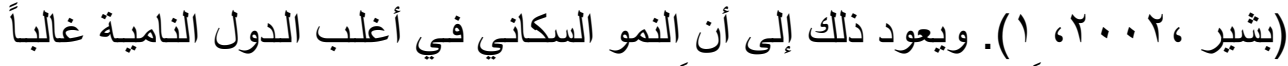

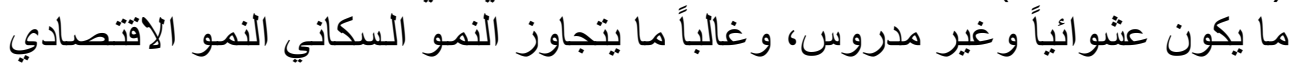

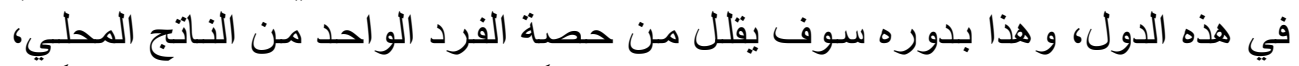

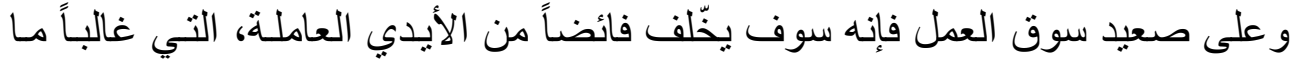

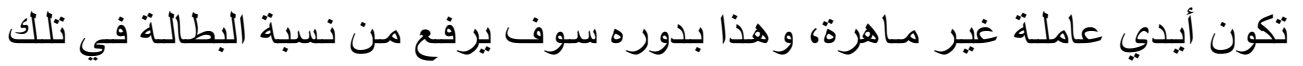

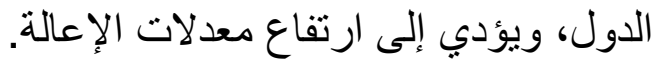

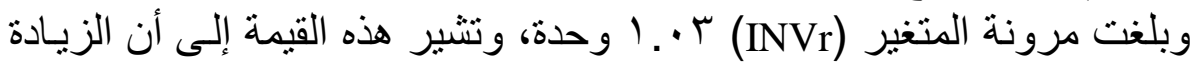
الحاصلة في هذا المتغير وبنسبة ( الفرد الواحد من الناتج المحلي الإجمالي (PCGDP

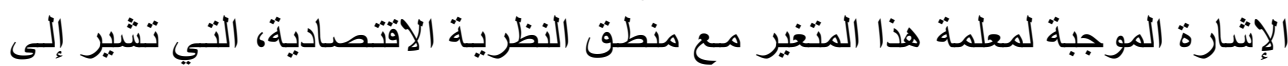

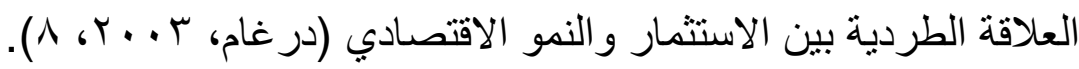

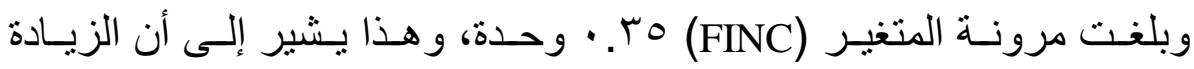

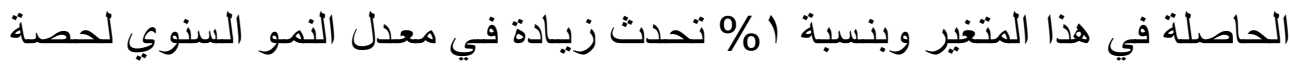

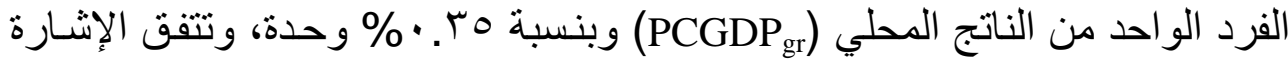
الموجبة لمعلمة هذا المتغير مـع منطق النظريـة الاقتصادية، التي تشير إلى العلاقة

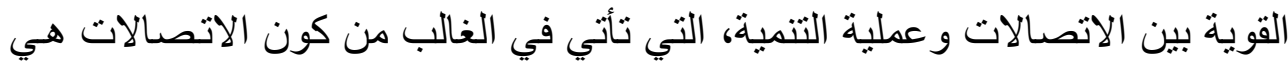

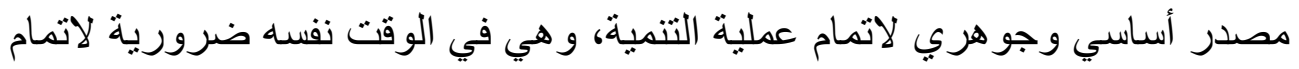

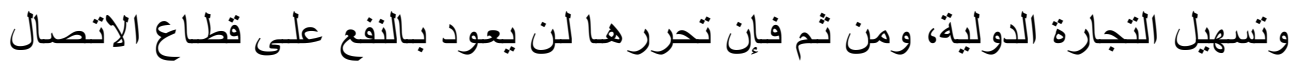

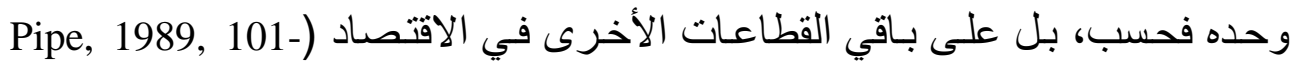

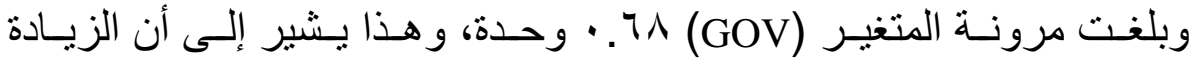

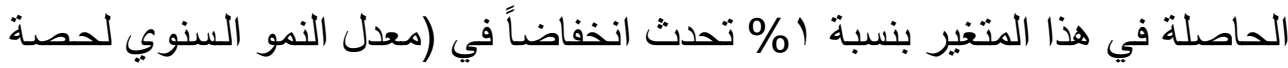

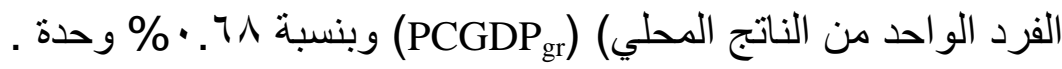




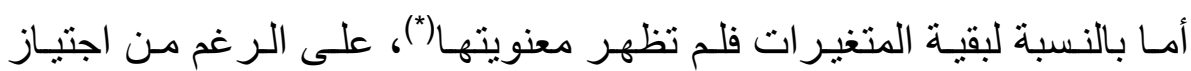

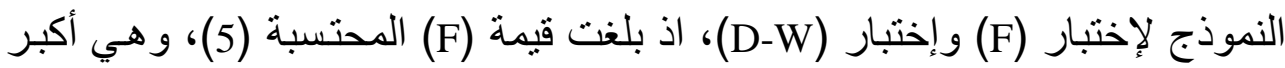

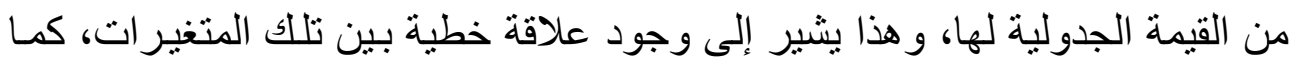

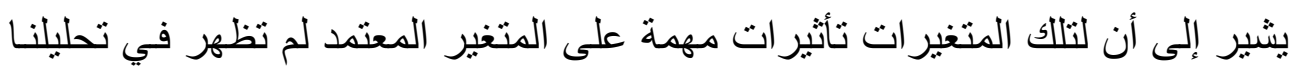
هذا.

الاستنتاجات و المقترحات

توصل البحث إلى مجمو عة من الاستنتاجات و المقترحات تتمثل في الآتي :

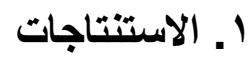

في سياق الدراسة السابقة تم التوصل إلى مجمو عة من الاستنتاجات الآتية :

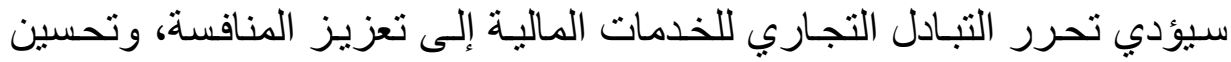

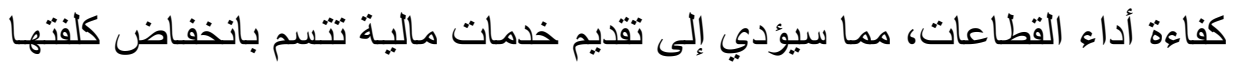
وتحسن نوعيتها. • سيؤدي تحرر الخدمات المالية إلى جذب الاستثمار ات الأجنبية المباثرة، و وإعادة

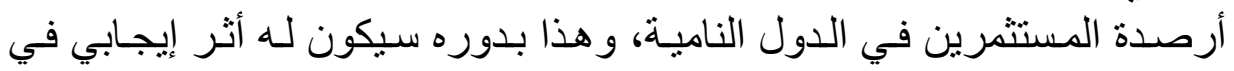

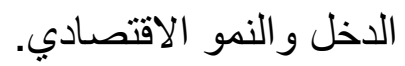

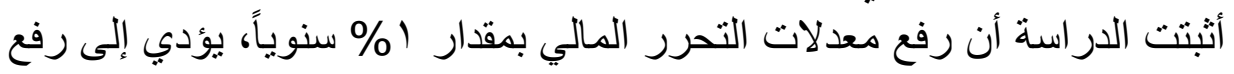

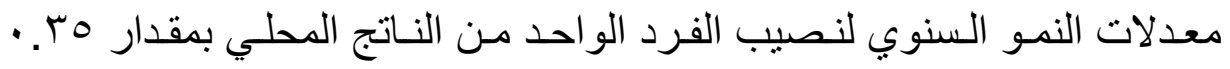
وحدة.

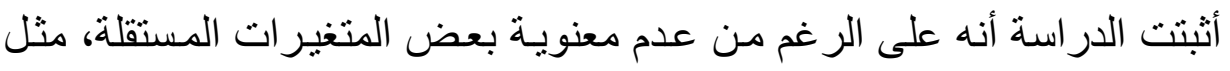

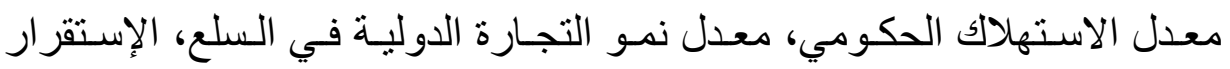

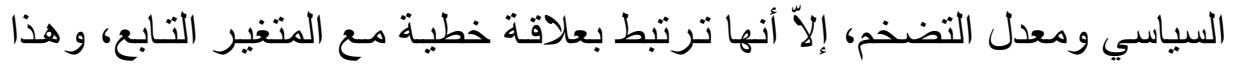
يعني أن لهذه المتغيرات آثار اً مهمة في المتغير التابع لم تظهر في تحليلنا هذا.

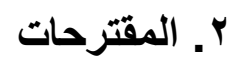

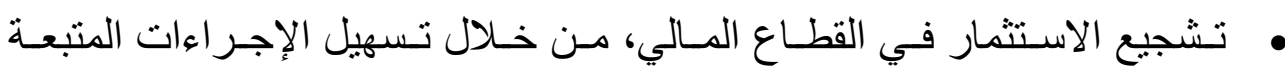
وتبسيطها في منح الرخص و التصاريح لتشجيع الاستثمار في هذا القطاع.

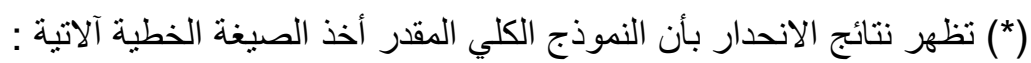
PCGDP $_{\text {gr }}=2.900 \_1.329\left(\mathrm{POP}_{\mathrm{gr}}\right)+0.0166$ (TRDgr) +.172 (POLS)+ 0.0002 (INFL)+ 0.1213 (INVR) $-0.1558(\mathrm{GOV})+0.1975$ (FINC)
(2.356)
(1.884)
(3.908)
(.343)
(.388)
(.289)
$\mathrm{R} 2=0.70$
$\mathrm{F}=5$
$\mathrm{D}-\mathrm{W}=2.520$

(2.850) 


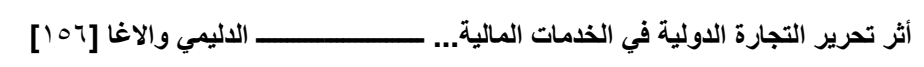

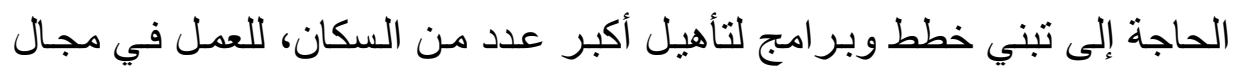

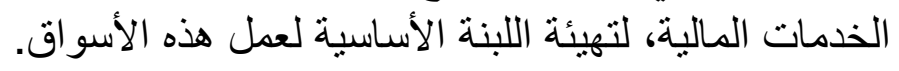

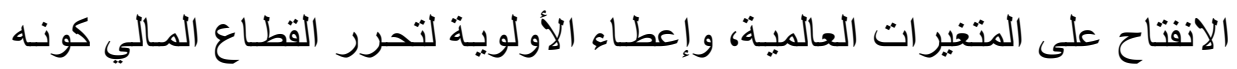

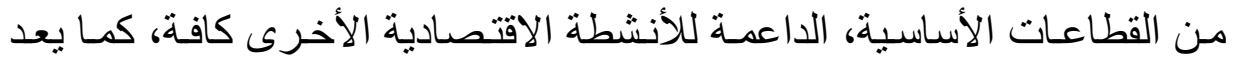

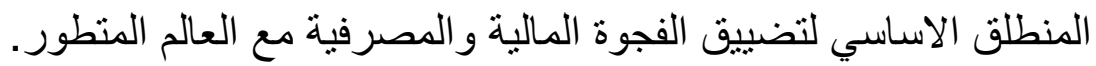

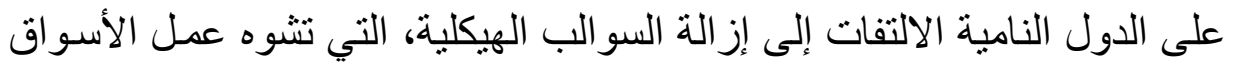

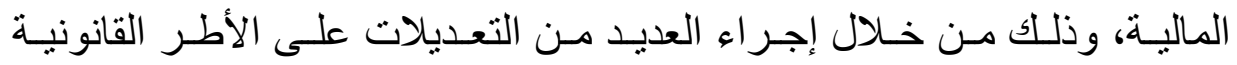

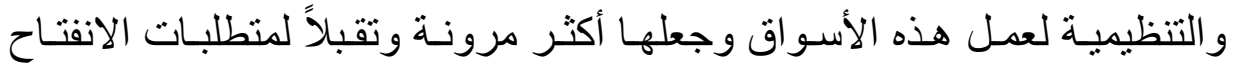
الاقتصادي.

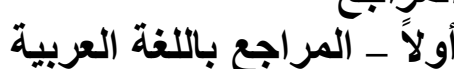

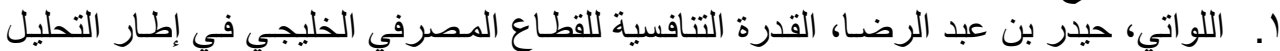

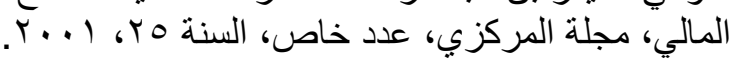

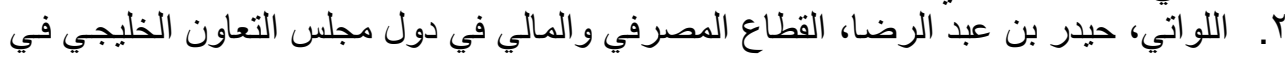

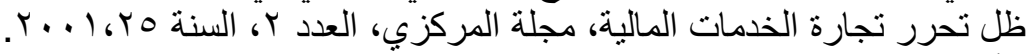

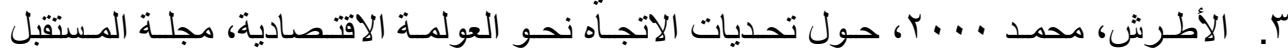

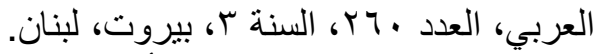

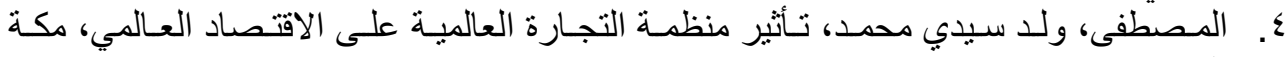
www.aljazeera.net/in-depth/international-com/2001/10/10-27-7.htm

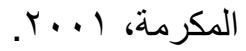
•. العاني، عماد محمد، اندماج الأسواق المالية الدولية: اسبابه و انعكاساته على الاقتصاد العالمي،

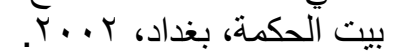

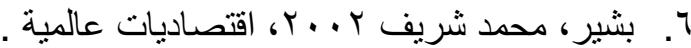
www.islamonline.net/ arabic/economics/2002/07/article og.shtm1-101k.

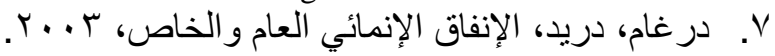
www.mafhoum.com/syr/articles/dergham/dergham1.htm1-29k.

^. كاظم، اموري وباسم شليية مسلم، القياس الاقتصادي المتقدم النظريـة و التطبيق، مكتبة دنيا

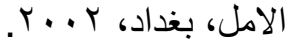

\section{ثانياً_ المراجع باللغة الأجنبية}

1. Randeep Rathindran,

E-Mail :(rrathindran@worldbank.org), (randeep@wam.umd.edu)

2. UNCTAD, Hand Book of international Trade and development statistics, United Nation, New York and Geneva, 1996-1997.

3. UNCTAD, Hand Book of statistics, United Nation, New York and Geneva, 2002.

4. United Nations, Human Development Report, New York, 2001.

5. United Nations, Statistical Year Book, New York and Geneva, 2002.

6. Adaity Mattoo, Measuring services Trade Liberalization and Its Impact on Economic Growth: An Illustration, 2001. www.sice.oas.org/geograph/services/mattoor.pdf. 
$(r \cdot)^{9} \cdot$

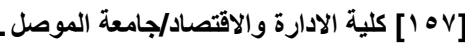

7. Andy Chui. "Corporate Groups Financial Liberalization and Growth: The case of Indonesia, 2000.

www.worldbank.org/research/projects/finstructure/pdf files/sheridan.df

8. Arturo Galindo, "Financial Liberalization and Growth: Empirical Evidence". World Bank, 2002.

www.worldbank.org/research/conferences/financial_globalization/Financial Liberalization_version 23.pdf.

9. Domenica Tropeano,"Financial Liberalization Economic Growth and Rentc", 2001. www.cidei.eco.uniromal.it/ lobby/papers/1c.tropeano.pdf.

10. Fernando de Mateo,"Trade in Services and The Developing Countries ,"Services and Development Potential :The Indian context ,UN,New York, 1989

11. G.Russell Pipe, "Telecommunications Services: Consideration for Developed Countries in Uruguay Round Negotiation ",Trade in Services Sectoral Issues :UN, New York, 1989.

12. Hiroshi Hirano, "Statement on the up coming WTO 2000 services Round", 1999. www.sonpo-or.jp/english/topics/eng-5599.pdf .

13. Jeffery Shafer, Free Trade in financial services, Economic perspectives : vol.1, no.1, 1996. www.use mbassy.it/pdf/ej/ijeeo496.pdf.

14. John R Harris,"The Effect Of Financial Liberalization on the Capital Structure and Investment Decisions of Indonesian Manufacturing Establishment ", The World Bank Economic Review: VOL.8, NO.1, 1994.

15. Jonas Vlachos, "International Financial Liberalization and Industry Growth",2002. www.iui.se/staff/Jonas V/fin/ib-indgrth.pdf.

16. Joseph F Francois, "Trade in Financial services: procompetitive Effects and Growth Performance", 1999. www.tinbergen.n1/discussion papers/990 28.pdf .

17. k.S Jomo,"Growth After the Asian Grisis ,"G-24 Discussion Paper Series :NO.10 ,UN, New York, and Geneva, 2001 .

18. Lefort \& Budnevich,"Capital -Account Regulation and Macroeconomic Policy ", International Monetary and Financial Issue For The 1990s:VOL.VIII, UN, New York and Geneva, 1997.

19. Mansoor Dailami, Financial Openness, Democracy, and Redistributive Policy, 2000. www.worldbank.org/wbi/infrafin/pubs/2372openness.html - 23k 